\title{
The influence of monetary incentives on context processing in younger and older adults: an event-related potential study
}

\author{
Hannah Schmitt • Nicola K. Ferdinand • Jutta Kray
}

Published online: 10 February 2015

(C) Psychonomic Society, Inc. 2015

\begin{abstract}
Recent evidence has indicated that neuronal activity related to reward anticipation benefits subsequent stimulus processing, but the effect of penalties remains largely unknown. Since the dual-mechanisms-of-control theory (DMC; Braver \& Barch, Neuroscience and Biobehavioral Reviews, $26,809-81,2002$ ) assumes that temporal differences in context updating underlie age differences in cognitive control, in this study we investigated whether motivational cues (signaling the chance to win or the risk to lose money, relative to neutral cues) preceding context information in a modified AXCPT paradigm influence the temporal stages of context processing in younger and older adults. In the behavioral data, younger adults benefited from gain cues, evident in their enhanced context updating, whereas older adults exhibited slowed responding after motivational cues, irrespective of valence. Event-related potentials (ERPs) revealed that the enhanced processing of motivational cues in the $\mathrm{P} 2$ and $\mathrm{P} 3 \mathrm{~b}$ was mainly age-invariant, whereas age-differential effects were found for the ERP correlates of context processing. Younger adults showed improved context maintenance (i.e., a larger negative-going $\mathrm{CNV}$ ), as well as increased conflict detection (larger N450) and resolution (indicated by a sustained positivity), whenever incorrect responding would lead to a monetary loss. In contrast, motivationally salient cues benefited context representations (in cue-locked P3b amplitudes), but increased working memory demands during response preparation (via a temporally prolonged $\mathrm{P} 3 \mathrm{~b}$ ) in older adults. In sum, motivational valence and salience effects
\end{abstract}

Electronic supplementary material The online version of this article (doi:10.3758/s13415-015-0335-x) contains supplementary material, which is available to authorized users.

H. Schmitt $(\bowtie) \cdot$ N. K. Ferdinand · J. Kray

Department of Psychology, Saarland University,

66041 Saarbrücken, Germany

e-mail: h.schmitt@mx.uni-saarland.de differentially modulated the temporal stages of context processing in younger and older adults. These results are discussed in terms of the DMC theory, recent findings of emotion regulation in old age, and the relationship between cognitive and affective processing.

Keywords Context processing $\cdot$ Aging $\cdot$ Incentive $\cdot$ ERP . Motivation

\section{Introduction}

Successful behavior requires cognitive control mechanisms to support the representation of specified goals and provide the means to achieve them (Miller \& Cohen, 2001). From a variety of measures, it has become clear that cognitive control functions are particularly affected by aging (Braver et al., 2001; West, 1996). In daily life, however, certain goals are especially important, since pursuing them is potentially rewarding (Chiew \& Braver, 2011; Pessoa, 2008); thus, goaldirected representations may be influenced by their motivational value. Older adults seem to focus more on emotion regulation, in that they show enhanced attention and memory for positive relative to negative and neutral information (see Mather \& Carstensen, 2005). Hence, the question arises of whether cognitive control functions can be modulated by anticipatory reward and penalty, and whether the positive information provided by reward can reduce age-related differences in cognitive control. To address these questions, in the present study we applied motivational cues in a cognitive control task with younger and older adults.

In the dual-mechanisms-of-control theory (DMC), context representations (e.g., task instructions, rules, or goals) are a core component of cognitive control and are assumed to bias the 
processing and storage of goal-relevant representations within working memory (WM; see Braver \& Barch, 2002; Braver, Gray, \& Burgess, 2007). Successful context processing includes the abilities to steadily maintain context information against distraction and to flexibly update context information when confronted with new or reward-predicting information. The theory postulates that specific neural functions underlie context processing, and therefore has been used as a reference to explain the mechanisms underlying the cognitive control deficits observed in aging (Braver \& West, 2008; West, 2004). Specifically, context maintenance is thought to rely on sustained activity of dorsolateral prefrontal cortex (DL-PFC) neurons, whereas dopamine (DA) release to the DL-PFC after novel or reward-predicting cues is assumed to update context representations by regulating the access of new information into PFC (Braver, 2012; Braver \& Cohen, 2000; Braver et al., 2007). Since the PFC (Raz, 2000) and the DA system (Bäckman \& Farde, 2005) are known to be strongly affected by aging, age-related deficits in the ability to update and to maintain context information are expected. These abilities have usually been examined by applying the AX continuous-performance task (AX-CPT; Braver \& Barch, 2002), in which information about a context cue is required for correct responding on a subsequent probe. Behavioral performance has revealed that younger adults usually engage strongly in updating and maintaining context information at the time that the context cue is presented, and that they prepare for the upcoming response in a proactive manner. Older adults, in contrast, typically engage less in advance preparation, and therefore reactivate context information when confronted with the probe, in a reactive manner (Braver, 2012; West \& Schwarb, 2006). These differences in context processing can also be seen in a trade-off between cue- and probe-related activation in lateral PFC in younger relative to older adults, on the basis of functional magnetic resonance imaging (fMRI) results (Paxton, Barch, Racine, \& Braver, 2008).

Recently, we investigated age-related temporal differences in context processing in cue- and probe-related event-related potentials (ERPs; Schmitt, Ferdinand, \& Kray, 2014; Schmitt, Wolff, Ferdinand, \& Kray, 2014) in a modified AX-CPT (Lenartowicz, Escobedo-Quiroz, \& Cohen, 2010). In this task, correct responses to probes on context-dependent (c-dep) trials were dependent on the context provided by a preceding cue, since stimulus-response (S-R) mappings to probes were reversed. In contrast, on context-independent (c-indep) trials, correct responses to probes could be given without context information, since the response assignments to the probes were exactly the same. Thus, it was possible to analyze context effects - that is, differences between c-dep trials, requiring context updating, maintenance, and S-R reconfiguration, and c-indep trials, not requiring context updating or advanced task reconfiguration. We uncovered initial evidence for an age-related shift from a proactive toward a reactive control mode, in that younger adults exhibited larger parietal P3b amplitudes on c-dep than on c-indep trials.
Although the functional interpretation of the P3b is open to debate (see Donchin \& Coles, 1988; Verleger, Jaśkowski, \& Wascher, 2005), larger P3b amplitudes to target than to standard stimuli in the oddball paradigm have suggested a larger amount of resource allocation and updating of task relevance in WM (Donchin \& Coles, 1988; Kray, Eppinger, \& Mecklinger, 2005). Hence, the context effect in the P3b could indicate that younger adults were strongly engaged in context updating and task reconfiguration after cue presentation when the cue was necessary in order to infer the correct response on c-dep trials. Older adults, particularly those showing poor behavioral performance, exhibited comparable P3b amplitudes to all context cues, irrespective of whether context updating was required (Schmitt, Ferdinand, \& Kray, 2014). However, older adults who showed performance equivalent to that of younger adults seemed to compensate for the lack of cue-related context updating via reactive control at the time that the probe was presented, which was indicated by larger negative-going N450 amplitudes on cdep than on c-indep trials (Schmitt, Wolff, et al., 2014). So far, the N450 has been extensively studied in the Stroop task (Eppinger, Kray, Mecklinger, \& John, 2007; Rebai, Bernard, \& Lannou, 1997; West, 2004), and larger N450 amplitudes on incongruent than on congruent Stroop stimuli suggest a role in interference detection (Liotti, Woldorff, Perez, \& Mayberg, 2000; Rebai et al., 1997; West, 2004). This effect can be separated from a subsequent sustained potential (SP) that correlates with behavioral performance, and therefore seems to reflect processes of conflict resolution (Liotti et al., 2000; West, 2004; West \& Alain, 2000) or response selection (West, Jakubek, Wymbs, Perry, \& Moore, 2005). Hence, the larger N450 to ambiguous probes on c-dep than on c-indep trials in older adults in our previous studies might indicate conflict detection concerning the correct response, which is linked to reactive control. Finally, context effects, but no age-related differences therein, were also found in a cue-locked contingent negative variation $(\mathrm{CNV})$ in the previous studies. The CNV has been related to task expectation and effortful preparation for an upcoming task (Wild-Wall, Hohnsbein, \& Falkenstein, 2007). Thus, the larger CNV amplitudes on c-dep than on c-indep trials in the previous studies might indicate the maintenance of context information for response preparation that is essential on c-dep trials.

In accordance with the DMC theory, which assumes that context updating is triggered by reward, recent studies have shown that motivational and emotional manipulations, such as positive mood induction or performance-contingent reward, influence performance on cognitive control tasks (Fröber \& Dreisbach, 2014; Pessoa, 2008), although in somewhat different ways (Chiew \& Braver, 2014). It is generally assumed that this influence is mediated by DA (Ashby, Isen, \& Turken, 1999; Chiew \& Braver, 2011). DA neurons in the ventral tegmental area of the midbrain exhibit phasic DA release after unpredicted reward and after cues predicting future reward (Schultz, 2002), which can be forwarded to frontal cortices. 
There is evidence that the PFC integrates motivational and cognitive processes, since reward expectations increased WM maintenance in the lateral PFC in macaques (Leon \& Shadlen, 1999; Watanabe, 1996). There is also evidence that the avoidance of penalty may be rewarding and likewise linked to DA (Ikemoto \& Panksepp, 1999). Although reward and penalty have contrasting motivational value - that is, reward holds a positive value as we try to seek it, whereas penalty has a negative connotation as we try to avoid it-they possess similar motivational saliences, since both are behaviorally relevant (see Bromberg-Martin, Matsumoto, \& Hikosaka, 2010). Different populations of DA neurons might be responsible for encoding motivational value and salience. Whereas motivational-value-coding DA neurons are typically excited by rewarding events and inhibited by aversive events, motivational-salience-coding DA neurons are excited by both rewarding and aversive events, but inhibited by neutral events. Therefore, they are important for detecting and orienting to stimuli of high behavioral importance (see Bromberg-Martin et al., 2010). Most importantly for the present study, motivational-salience-coding neurons have been shown to project to dorsal and lateral prefrontal areas, indicating that both rewarding and aversive events may influence the brain regions involved in cognitive control (Bromberg-Martin et al., 2010; Pessoa, 2008).

Research on tasks assessing the use of context cues in younger adults - for instance, with the AX-CPT or cued task switching - has shown that prospective reward shortens latencies, relative to blocks without reward. This boost was on average not at the cost of errors, ruling out a pure speedaccuracy trade-off (Braver, Paxton, Locke, \& Barch, 2009; Jimura, Locke, \& Braver, 2010; Kleinsorge \& Rinkenauer, 2012; Locke \& Braver, 2008). Error patterns in the AX-CPT suggested that the improvement occurred through an increase in proactive control on reward trials - that is, a shift toward context processing in a preparatory manner (Chiew \& Braver, 2013, 2014). In task switching, larger effects of reward were found on mixed than single blocks, with switch costs decreasing to nonsignificance (Kleinsorge \& Rinkenauer, 2012), indicating that anticipated reward enhances performance when cognitive control demands are high. However, since performance on single blocks is usually already good, there is no room for large improvements. Surprisingly, only a few studies have investigated the effects of anticipated penalty on cognitive control performance (Braver et al., 2009; Krawczyk \& D'Esposito, 2013; Locke \& Braver, 2008). In the AX-CPT, anticipated penalties have slowed reaction times and reduced errors on no-go trials, in which participants had to withhold a response (Braver et al., 2009). Contrary to under reward conditions, inspection of error rates suggested increased reactive control. Nevertheless, comparison between performance on reward and penalty trials in this study was hampered, since penalties were applied only after errors on a specific type of no-go trials. In contrast, both reward and penalty incentives led to faster reaction times (i.e., detection) in an endogenously cued attention task, which was interpreted as improved perceptual sensitivity and sharpened attention during motivationally salient conditions (Engelmann \& Pessoa, 2007). Again, this effect was not due to a speed-accuracy trade-off (Engelmann \& Pessoa, 2007). Thus, there is evidence that both anticipated rewards and penalties benefit goal-relevant performance in younger adults. Yet the precise mechanisms underlying this benefit and the control processes affected by motivational salience remain unclear. ERPs can help to determine whether the influence of reward and penalty on cognitive control is associated with processes of context updating, task reconfiguration, or maintenance, linked to proactive control (Lenartowicz et al., 2010; Schmitt, Ferdinand, \& Kray, 2014), or to processes of conflict detection and response selection, linked to reactive control (Krebs, Boehler, Appelbaum, \& Woldorff, 2013; Schmitt, Wolff, et al., 2014; West \& Alain, 2000; West et al., 2005), or to both.

Some first evidence has suggested that reward anticipation increases preparation for an upcoming task, reflected in ERPs (Gruber \& Otten, 2010; Halsband, Ferdinand, Bridger, \& Mecklinger, 2012). In a memory study by Gruber and Otten (2010), the to-be-remembered words during encoding were preceded by cues indicating whether successful recognition in the test phase would be rewarded with a high or a low monetary bonus. Larger P2 amplitudes, indicating automatic, early attentional processes of stimulus discrimination (Carretié, Hinojosa, Martín-Loeches, Mercado, \& Tapia, 2004; Olofsson, Nordin, Sequeira, \& Polich, 2008) and feature detection (Luck \& Hillyard, 1994), as well as larger P3blike amplitudes (Donchin \& Coles, 1988), were found to motivational cues announcing a high, as compared to a low, reward. Critically, the larger P2 and P3b amplitudes after reward cues in the study predicted successful recollection only for words associated with high reward (Gruber \& Otten, 2010). Thus, the neural activity required for the successful preparation (here, encoding) of an upcoming event seems to be enhanced by the motivation to gain reward. This modulation of the P3b by reward expectancy is in line with results from other studies showing larger P3b amplitudes for reward trials than for trials without reward (Begleiter, Chou, \& Aunon, 1983; Krebs et al., 2013; Parvaz, Konova, Tomasi, Volkow, \& Goldstein, 2012), as well as for high- as compared to lowreward conditions (Capa, Bouquet, Dreher, \& Dufur, 2013; Goldstein et al., 2006). Recently, Krebs and colleagues applied a Stroop task and found increased P3b amplitudes to reward-predicting cues, which were interpreted as increased preparatory attention toward critical features of the upcoming Stroop stimulus that were essential to obtain later reward. Furthermore, in a task-switching paradigm, larger P3b amplitudes during response execution on reward trials were associated with a greater investment in WM benefiting fast reaction times (Capa et al., 2013). In addition, the CNV has also been 
shown to be linked to reward expectancy, since trials indicating reward for fast and correct responses produced larger CNV amplitudes (Capa et al., 2013; Falkenstein, Hoormann, Hohnsbein, \& Kleinsorge, 2003; but see Goldstein et al., 2006). Finally, the Stroop study by Krebs et al. demonstrated a reward modulation of conflict-related components, such as the N450 and a subsequent positivity (termed the late positivity component [LPC] by Krebs et al., 2013; or the sustained potential [SP] by West \& Alain, 2000; West et al., 2005), in that they peaked earlier during trials with than in those without reward, where no amplitude differences were reported. This temporal shift has been interpreted as an earlier start of conflict processing, which was triggered by enhanced attention toward relevant features of the Stroop stimulus, linked to the preceding P3b in Krebs et al.'s study.

\section{The present study}

Taken together, age differences in cognitive control have been associated with age-related changes in the temporal dynamics of context processing by means of ERPs. Younger adults usually display larger parietal $\mathrm{P} 3 \mathrm{~b}$ amplitudes on trials requiring context updating and task reconfiguration in a preparatory manner, indicating a cue-based, proactive control mode. Older adults do not differentiate between context conditions in cue-related P3b amplitudes, but instead rely on a probebased, reactive control mode, indicated by a larger N450 during response preparation (Schmitt, Wolff, et al., 2014). Research in an fMRI study in younger adults showed that reward cues shifted context processing toward a larger reliance on proactive control (Chiew \& Braver, 2013; Kleinsorge \& Rinkenauer, 2012; Locke \& Braver, 2008). However, although the DMC theory assumes that proactive context updating is promoted by reward, research so far has lacked evidence for whether reward cues can be used to modulate the temporal dynamics of context processing in older adults.

Previous studies have not consistently applied penalty manipulations on cognitive control tasks in order to examine whether motivationally salient reward and penalty operate via common mechanisms or whether valence affects cognitive control. This aspect might be particularly important in the elderly, since they seem to focus on positive rather than on negative and neutral information. This so-called positivity effect has been found in increased attention and improved memory for positive events, and is interpreted as a top-down mechanism to support emotional gratification (Mather \& Carstensen, 2005; Reed \& Carstensen, 2012). There is also evidence that different phases in cognitive processing are differentially sensitive to valence and salience information, which can be measured by means of ERPs. For example, Ferdinand and Kray (2013) reported that the feedbackrelated negativity in a reinforcement-learning task signals the detection of salient expectancy violations irrespective of their valence, whereas the subsequent P300 differentiated between negative and positive feedback.

In sum, in the present study we aimed at examining whether performance-contingent reward and penalty can modify the temporal dynamics of updating and maintaining context information in younger and older adults. We were interested in the stage of context processing that is affected by this modulation - that is, in cue-related ERPs (P3b, CNV), indicating context updating, task reconfiguration, and maintenance, or in probe-related ERPs (N450, SP/LPC), reflecting conflict detection and response selection. To this end, we applied a modified AX-CPT (see Schmitt, Ferdinand, \& Kray, 2014) and included motivational cues (neutral, gain, loss) at the start of each trial, indicating the possibility to win or lose a monetary bonus. In accordance with the literature, (1) The difference between trials with gain and loss cues versus trials with neutral cues will be termed motivational salience effect, and (2) the difference between the two motivationally salient cues (gain, loss) will be termed the motivational valence effect (see Bromberg-Martin et al., 2010). Thus, our paradigm allows for comparing performance and the ERPs associated with context processing between motivationally salient and neutral, and between motivationally valenced cues.

In addition to replicating our earlier results on context updating (Schmitt, Ferdinand, \& Kray, 2014; Schmitt, Wolff, et al., 2014), we expected that motivationally salient cues should benefit behavioral performance: That is, we expected faster responding and lower error rates, especially on c-dep trials, in which cognitive control demands are high (Bromberg-Martin et al., 2010; Chiew \& Braver, 2013; Ikemoto \& Panksepp, 1999; Kleinsorge \& Rinkenauer, 2012). On the electrophysiological level, ERPs time-locked to the presentation of the motivational cues, the context cues, and the probes could be examined, and the effects of motivational salience and valence - as well as age differences therein - could be compared. Motivational cues signaling potential reward should evoke larger $\mathrm{P} 2$ and $\mathrm{P} 3 \mathrm{~b}$ amplitudes than would neutral cues (Gruber \& Otten, 2010), and, since penalty was important for the behavioral outcome, similar ERP modulations were expected to cues signaling potential loss. On the basis of DMC theory and empirical findings on cognitiveaffective interactions (Braver \& Barch, 2002; Gruber \& Otten, 2010), motivational cues were predicted to modulate the different stages of context processing. Specifically, in younger adults, we expected larger context effects (in the $\mathrm{P} 3 \mathrm{~b}$ and $\mathrm{CNV}$ locked to the context cue) during both sorts of motivationally salient trials, indicating enhanced proactive control. In contrast, but in line with research on the positivity effect (see Mather \& Carstensen, 2005), we expected that older adults would show a modulation of context effects by motivational valence - that is, greater performance benefits and an improvement in context processing on gain than on 
loss trials. However, the precise processing stages at which the modulation of context effects in old age would take placethat is, during either cue-based (the P $3 \mathrm{~b}$ ) or probe-based (the N450) processing, linked to pro- or reactive control, respectively - are an open question. One possible outcome, derived from the neurobiological framework of the DMC theory (Braver \& Barch, 2002), could be that reward trials trigger proactive control in older adults, as reflected in increased cue-related context effects (indicated by the P3b).

\section{Method}

Participants

A total of 25 younger and 24 older adults participated in the study. The older adults were recruited from a participant pool, and the younger adults were students at Saarland University. One participant from the younger age group had to be excluded due to latencies more than three standard deviations above the corresponding group mean in the AX-CPT, and one participant from the older age group did not finish the experiment. Additionally, six younger and five older participants were excluded because they did not have the necessary total of 16 artifact-free trials for the electroencephalogram (EEG) analysis. ${ }^{1}$

The final sample included 18 younger adults (mean age = 23.8 years, age range $=19-28$ years; $50 \%$ males $/ 50 \%$ females $)$ and 18 older adults (mean age $=73.0$ years, age range $=69$ 78 years; $56 \%$ males $/ 44 \%$ females). According to self-report, all of the participants had normal or corrected-to-normal vision and no signs of color-blindness, and were free of neurological or psychological disorders. The participants performed three psychometric tests in order to show the representativeness of the age groups in terms of fluid and crystallized intelligence measures. The Digit-Symbol Substitution Test (DSST; adapted from Wechsler, 2008) measured speed of processing; the counting span task (CS; adapted from Unsworth, Heitz, Schrock, \& Engle, 2005) served as a WM span measure, and the spot-aword test (Lehrl, 1977; Lindenberger, Mayr, \& Kliegl, 1993) was used as an indicator of vocabulary. In line with the twoprocess model of intellectual development (Baltes, Lindenberger, \& Staudinger, 1998), we found age differences in the fluid domain of intelligence. Younger adults performed better than older adults in the DSST, $F(1,34)=70.8, p<.001$, $\eta_{\mathrm{p}}{ }^{2}=.68$, and in the CS, in terms of both the number of correctly remembered sequences, $F(1,34)=15.6, p<.001, \eta_{\mathrm{p}}{ }^{2}=.32$, and the number of correctly remembered positions of single numbers, $F(1,34)=10.0, p<.01, \eta_{\mathrm{p}}^{2}=.23$. In the spot-a-word test, an indicator of crystallized intelligence, older adults performed

\footnotetext{
${ }^{1}$ Note that the high number of excluded participants was due to the exclusion of participants with less than 16 artifact-free trials in any ERP condition.
}

better than younger adults, $F(1,34)=24.7, p<.001, \eta_{\mathrm{p}}{ }^{2}=.42$. The results of the three intellectual control variables and the characteristics of the sample are displayed in Table 1.

Tasks and stimuli

Participants performed a modified version of the AX-CPT (see Schmitt, Ferdinand, \& Kray, 2014; adapted from Lenartowicz et al., 2010) to measure context processing by means of ERPs (see Fig. 1a and b). Each trial started with a fixation cross $(250 \mathrm{~ms})$, followed by a motivational cue (1, $000 \mathrm{~ms}$ ) indicating the incentive value of the subsequent cueprobe combination. On neutral trials, the motivational cue was a picture of a neutral (closed) moneybag surrounded by a black frame. On gain trials, a picture of a gain moneybag, with money falling into the bag, was surrounded by a green frame, and on loss trials, a picture of a loss moneybag, showing money dropping out of the bag, was surrounded by a red frame. Participants were instructed that the gain cue indicated the possibility to win money if they responded correctly, and that the loss cue indicated the risk to lose money if they responded incorrectly. On neutral trials, the monetary value remained constant, irrespective of the response accuracy. The motivational cue was followed by a blank interval $(500 \mathrm{~ms})$, the context cue $(750 \mathrm{~ms})$, and another blank $(750 \mathrm{~ms})$. The context cue indicated whether the subsequent trial was c-dep or c-indep. On c-dep trials, the correct responses to the probes were dependent on the preceding context cue and were exactly reversed for the two cue-probe combinations: Participants were instructed to press the left key when the picture of the bird followed the picture of the young woman, and the right key when the picture of the cat followed the picture of the young woman. These $\mathrm{S}-\mathrm{R}$ assignments were reversed when the bird and the cat followed the picture of the old man.

Table 1 Sample characteristics and results of all psychometric measures (means and standard deviations)

\begin{tabular}{|c|c|c|c|c|}
\hline \multirow[t]{2}{*}{ Measure } & \multicolumn{2}{|c|}{ Younger Adults } & \multicolumn{2}{|c|}{ Older Adults } \\
\hline & $M$ & $S D$ & $M$ & $S D$ \\
\hline$n$ & 18 & & 18 & \\
\hline Mean age (years) & 23.8 & 3.1 & 73.0 & 2.3 \\
\hline Age range (years) & $19-28$ & & $69-78$ & \\
\hline Gender distribution (\% female) & $50 \%$ & & $44 \%$ & \\
\hline Digit Symbol Substitution Test ${ }^{* *}$ & 70.6 & 7.7 & 45.0 & 10.3 \\
\hline \multicolumn{5}{|l|}{ Counting Span } \\
\hline Positions ${ }^{*}$ & 35.0 & 7.5 & 26.7 & 7.5 \\
\hline Sequences $^{* *}$ & 6.2 & 1.7 & 4.1 & 1.6 \\
\hline Spot-a-word $^{* *}$ & 23.8 & 3.4 & 28.8 & 2.6 \\
\hline Money won (euros) ${ }^{*}$ & 8.1 & 0.7 & 7.3 & 0.7 \\
\hline
\end{tabular}

${ }^{*} p<.01,{ }^{* *} p<.001$ significant age difference 
a)

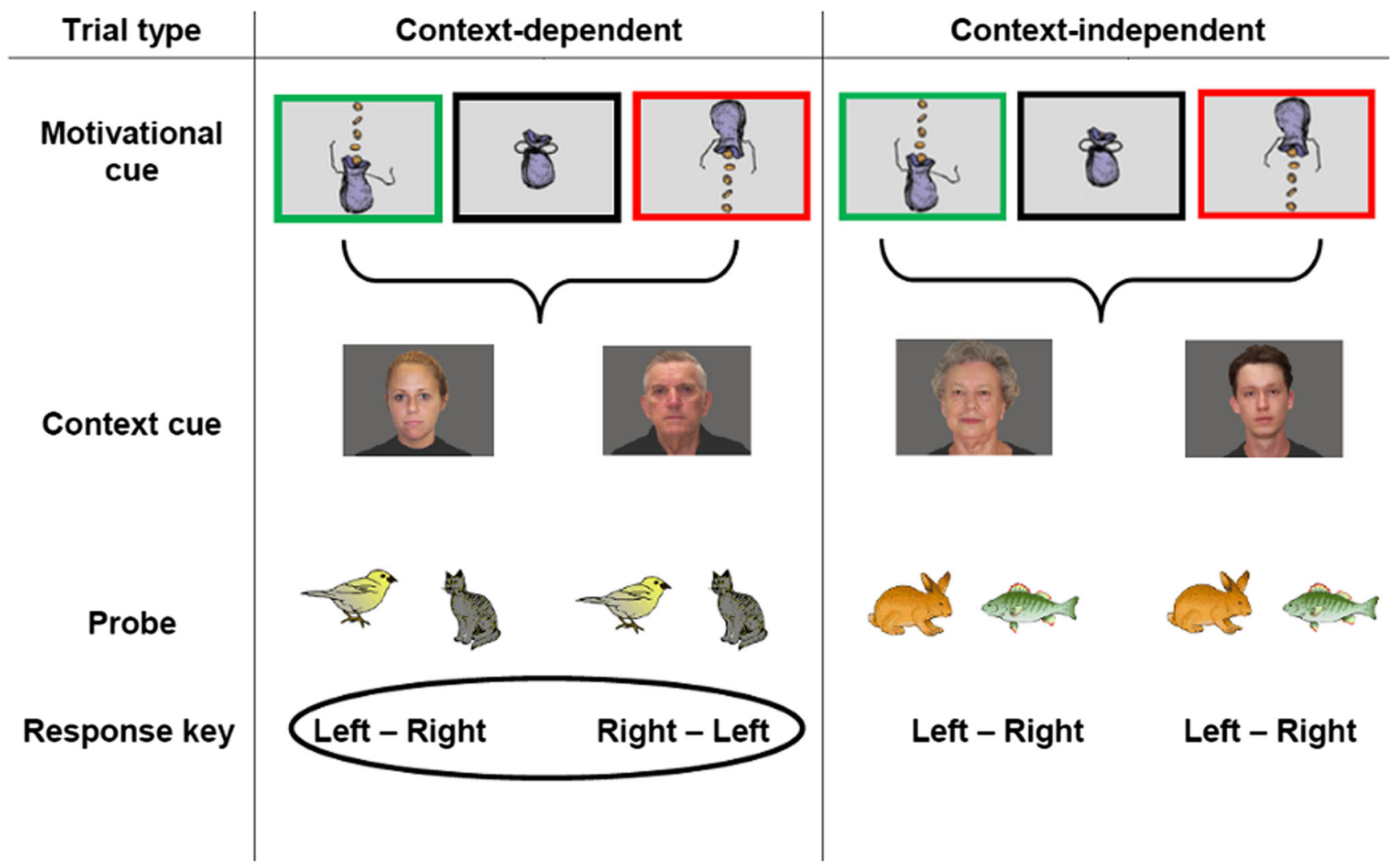

b)

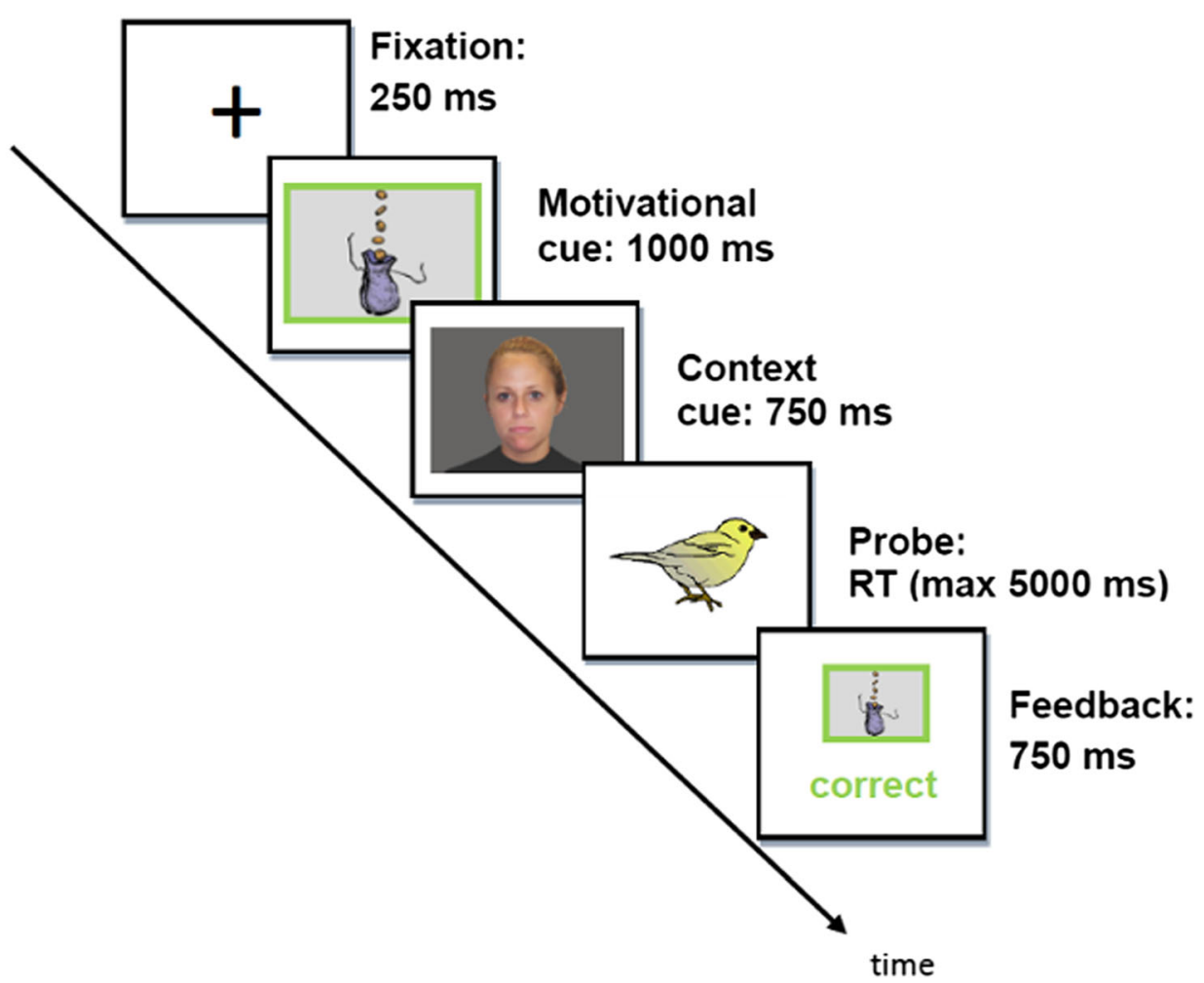


Fig. 1 (a) Example of the assignments of motivational cues, context cues, and probe pictures to correct response keys on c-dep and c-indep trials. On c-dep trials, the correct responses to probes after presentation of the context cues were exactly reversed; for example, participants had to press the left response key when the bird followed the younger woman, whereas they had to press the right key when the bird followed the older man. Thus, the correct response to probes depended on the information about the preceding context cue. On c-indep trials, the correct responses to the probes were the same for both context cues; for example, participants always had to press the left key if they saw the picture of the fish, and the right key if they saw the picture of the rabbit. Thus, these correct responses were independent of the context cue (see Schmitt, Ferdinand, \& Kray, 2014). Motivational cues preceded the presentation of the context cue and indicated the chance to win money on the current trial (indicated by money falling into the bag, surrounded by a green frame), the risk to lose money (indicated by money falling out of the bag, surrounded by a red frame), or a neutral trial (indicated by a closed money bag, surrounded by a black frame). (b) Trial procedure and stimulus presentation times in the modified AX-CPT. In the figure, blank screens are omitted for clarity; see the Method section for the durations of the blank screens

Hence, participants were to press the right key when the picture of the bird followed the picture of the old man, and the left key when the picture of the cat followed the picture of the old man (see Fig. 1a). On c-indep trials, the correct responses to the probes were independent of the preceding context cue. Participants were instructed to press the left key when the picture of the rabbit followed the picture of the old woman, and the right key when the picture of the fish followed the picture of the old woman. The same S-R assignments were required when the fish and the rabbit followed the picture of the young man (see Fig. 1a). Probes were presented for 5,000 ms or until the participant responded. If the response was not given within $5,000 \mathrm{~ms}$ after probe presentation, the trial was considered a time out. The probe was then followed by another blank (500 ms). Finally, feedback ("correct," "incorrect," or "too slow") was presented for $750 \mathrm{~ms}$, containing information about the response correctness and the achieved outcome. The intertrial interval was $500 \mathrm{~ms}$. Participants were instructed to respond as quickly and as accurately as possible. To ensure high motivation, participants were told that their achieved bonus would be an additional reimbursement to their participation. As in our previous study (Schmitt, Ferdinand, \& Kray, 2014), we used pictures of young and old faces as the context cues (Minear \& Park, 2004) and pictures of animals as the probes (i.e., rabbit, bird, cat, and fish, from the database by Rossion \& Pourtois, 2004). These stimuli were presented in a $3.5 \times 5.5 \mathrm{~cm}$ black frame at the center of a 24-in. monitor on a gray background.

The experiment was composed of 12 blocks with 48 trials each, yielding a total of 576 trials per participant. Each block consisted of both types of trials - c-dep and c-indep - which were equally distributed across the three motivational conditions (gain, loss, and neutral cues). This led to 96 trials in each of the six conditions (two context conditions multiplied by three motivational conditions). After each block a rest period was mandatory, and participants received feedback about their scored money that was calculated by subtracting the amount of money lost on loss trials from the money won during gain trials. At the end of the whole experiment, participants again received feedback about the total amount of money won during the 12 blocks. ${ }^{2}$ The assignment of context conditions to response keys was pseudorandom across participants, with the only constraint being that a young and an old facial picture were presented in both trial types for each participant. This led to four conditions that were equally assigned to the male and female participants in each age group.

\section{Procedure}

Participants first filled in an informed consent, a demographic questionnaire, and a handedness rating (Oldfield, 1971). Afterward, they were tested on the three psychometric tests described above and the AX-CPT. All of the participants were initially taught the meaning of the motivational cues and then performed three practice blocks of the AX-CPT. To familiarize participants with both trial types, the first practice block consisted of c-indep trials only, the second block of c-dep trials only, and the third practice block included both c-dep and c-indep trials. In the case that participants did not understand the task during the first practice run, the practice blocks were repeated. None of the participants had more than three repetitions of any practice block.

\section{EEG recording}

Participants were seated in a dimly lit, electrically shielded, and sound-attenuated chamber. EEG and electro-oculogram (EOG) activity were recorded simultaneously by Brain Vision Recorder (Brain Products, Germany) with $59 \mathrm{Ag}-\mathrm{AgCl}$ active electrodes (extended International 10-20 System; Jasper, 1958) in an elastic cap (Brain Products, Germany). The left mastoid served as a reference, and the ground electrode was placed at AFz. Impedances were kept below $20 \mathrm{k} \Omega$. The EOG measured vertical eye movements from two electrodes above and below the right eye, and horizontal eye movements from the outer canthi of both eyes. The EEG and EOG were low-pass filtered online $(250 \mathrm{~Hz})$, analog-to-digital converted (500 $\mathrm{Hz} \mathrm{SR}$ ), re-referenced to the linked mastoids, and band-bass filtered offline from 0.01 to $30 \mathrm{~Hz}$ prior to statistical analysis. Recording epochs that included eye movements were corrected by using a linear regression

\footnotetext{
${ }^{2}$ The amount of money won or lost was indicated by abstract feedback symbols together with written information about the correctness of the response - that is, there was no direct link between performance and the amount of money won or lost in a single trial. The outcome was calculated for each block by the difference between correct responses during gain and incorrect responses during loss trials, for both c-dep and c-indep trials. Since performance on c-indep trials was close to ceiling, only error rates below $5 \%$ were rewarded the highest amount of 75 cents, with decreasing rewards as error rates increased. Overall, the achieved outcome was always greater than zero.
} 
approach (Gratton, Coles, \& Donchin, 1983). Epochs with other recording artifacts were rejected before averaging whenever the standard deviation in a $200-\mathrm{ms}$ time interval exceeded $30 \mu \mathrm{V}$ in ocular electrodes or $20 \mu \mathrm{V}$ in the representative electrode $\mathrm{Cz}$. Data preprocessing also included a visual screening for artifacts in all electrodes, and additional artifacts were removed before averaging.

\section{Data analysis}

Practice blocks and trials with reaction times (RTs) faster than $100 \mathrm{~ms}$ were excluded from the analysis $(<0.1 \%$ of trials). The analysis of latencies was based on correct responses. The analysis of error rates included incorrect responses without time outs. ${ }^{3}$ ERPs were recorded time-locked to the onset of the motivational cue, the context cue, and the probe. The selections of the time interval and the electrodes for statistical analyses of the EEG components were based on the literature and on visual inspection (Karayanidis, Coltheart, Michie, \& Murphy, 2003; Krebs et al., 2013; Liotti et al., 2000; Schmitt, Ferdinand, \& Kray, 2014; West et al., 2005). In the motivational cue interval, we analyzed P2 and $\mathrm{P} 3 \mathrm{~b}$ amplitudes at three midline electrodes over frontal $(\mathrm{Fz})$, central $(\mathrm{Cz})$, and parietal $(\mathrm{Pz})$ areas. The $\mathrm{P} 2$ peaked around $200 \mathrm{~ms}$ after presentation of the motivational cue in older adults, and around $180 \mathrm{~ms}$ postcue in younger adults. Since the P2 latencies differed significantly between the two age groups, $F(1,34)=20.7, p<.001, \eta_{\mathrm{p}}{ }^{2}=.38$, we analyzed the mean $\mathrm{P} 2$ amplitudes in a time window from 170 to $230 \mathrm{~ms}$ after cue onset in the older age group, and in a time window from 150 to $210 \mathrm{~ms}$ after cue onset in the younger age group. Similarly, the P3b was significantly delayed in older as compared to younger adults, $F(1,34)=60.4, p<.001, \eta_{\mathrm{p}}{ }^{2}=.64$; therefore, mean P3b amplitudes were analyzed in a time window lasting from 440 to $640 \mathrm{~ms}$ after cue presentation in older adults, and from 360 to $560 \mathrm{~ms}$ in the younger adults. In the context-cue interval, the analyses focused on the amplitude of the P3b and the CNV at three midline electrodes over frontal $(\mathrm{Fz})$, central $(\mathrm{Cz})$, and parietal $(\mathrm{Pz})$ areas. The $\mathrm{P} 3 \mathrm{~b}$ peak latencies differed significantly between the age groups (at about $500 \mathrm{~ms}$ for younger and $570 \mathrm{~ms}$ for older adults), $F(1,34)=31.3, p<.001, \eta_{\mathrm{p}}{ }^{2}=.48$; thus, we defined the P3b time window as ranging from 400 to $600 \mathrm{~ms}$ for younger and from 470 to $670 \mathrm{~ms}$ for older adults, respectively. The CNV component was analyzed in a time window from 1,200 to 1,500 ms in both age groups (Schmitt, Ferdinand, \& Kray, 2014). Visual inspection of the proberelated ERPs revealed that (a) in younger adults, context effects reversed their ordering at $600 \mathrm{~ms}$ postprobe, suggesting two distinct components (i.e., P3b and N450), and (b) this was not

\footnotetext{
${ }^{3}$ Because of the long presentation time of the probe, time outs were generally rare and occurred in less than $0.1 \%$ of trials. Time outs were only produced by three younger and four older adults, who together generated only 13 time outs (out of 576 trials per participant).
}

clearly visible in the ERP waveforms of older adults, probably due to component overlap. Since this rendered the definition of time windows difficult, we decided to investigate ERPs by measuring mean amplitude difference waves (i.e., the context effects in neutral, gain, and loss trials) at three midline electrodes $(\mathrm{Fz}$, $\mathrm{Cz}, \mathrm{Pz}$ ) in a 300- to 600-ms and a 600- to 900-ms epoch after probe onset in both age groups.

In order to focus on the motivational influences on context processing, we refrain from reporting mere replications of agerelated differences in context effects (Schmitt, Ferdinand, \& Kray, 2014) in the Results section (but see the Supplementary material for complete analyses). Instead, for both the behavioral data and the ERPs, the effects of the motivational cues will be reported in terms of two a-priori-defined orthogonal contrasts: The first contrast compared mean performance and ERPs on neutral cues against the two motivational cues (termed the motivational cue salience effect) and was calculated by subtracting performance on neutral trials from the averaged performance on gain and loss trials. The second contrast compared mean performance and ERPs on valenced cues (termed the motivational cue valence effect) and was calculated by subtracting performance on loss trials from performance on gain trials (see Table 2). For both the behavioral data and ERPs in the context-cue-probe interval, the effects of the motivational cue salience and valence contrast on age differences in context effects were computed in an analysis of variance (ANOVA) including the factors Age Group (younger, older adults), Context Condition (c-dep, c-indep trials), and Anterior-Posterior (electrodes Fz, Cz, Pz; for the ERP data only). For all analyses, the alpha level was set to $\alpha=.05$. If necessary, Greenhouse-Geisser corrections for nonsphericity (Keselman \& Rogan, 1980) were applied, and epsiloncorrected $p$ values are reported together with epsilon values $(\varepsilon)$ and uncorrected degrees of freedom. To control for age differences in scalp distributions, ANOVAs were conducted using vector-normalized data (McCarthy \& Wood, 1985).

\section{Results}

\section{Behavioral data}

Only for the latency data, ${ }^{4}$ we found motivational effects on the context conditions. The ANOVA revealed a significant interaction between context condition and motivational cue valence,

\footnotetext{
${ }^{4}$ To take into account that all interactions including the factor Age Group may have been due to age differences in baseline performance, we also calculated the ANOVA on motivational cue valence and salience effects on age differences in context processing using the natural logarithms of the raw RTs (Kray \& Lindenberger, 2000). The results confirmed the analysis of the RT data in their main aspects: In younger adults, context effects were modulated by motivational cue valence, $F(1,17)=5.0, p<$ $.05, \eta_{\mathrm{p}}{ }^{2}=.23$, whereas context effects in older adults were modulated by motivational cue salience, $F(1,17)=17.3, p<.01, \eta_{\mathrm{p}}{ }^{2}=.50$.
} 
Table 2 Mean reaction times and error rates (standard errors in parentheses) for c-dep and c-indep trials across neutral, gain, and loss cues, and motivational salience and valence effects separately for younger and older adults

\begin{tabular}{|c|c|c|c|c|c|}
\hline Variable & Neutral & Gain & Loss & $\begin{array}{l}\text { Motivational } \\
\text { Salience Effect }\end{array}$ & $\begin{array}{l}\text { Motivational } \\
\text { Valence Effect }\end{array}$ \\
\hline \multicolumn{6}{|l|}{ Young Age Group } \\
\hline \multicolumn{6}{|l|}{$\mathrm{RTs}$ in $\mathrm{ms}$} \\
\hline c-dep & $652(26)$ & $619(22)$ & $642(26)$ & $22(10)$ & $-23(11)$ \\
\hline c-indep & $520(21)$ & $516(21)$ & $510(20)$ & $7(5)$ & $6(6)$ \\
\hline context effect & $132(14)$ & $103(12)$ & $132(13)$ & & \\
\hline \multicolumn{6}{|l|}{ Errors in $\%$} \\
\hline c-dep & $3.1(0.9)$ & $2.3(0.9)$ & $2.8(0.9)$ & $0.6(0.4)$ & $-0.5(0.5)$ \\
\hline c-indep & $0.5(0.2)$ & $0.6(0.3)$ & $0.4(0.2)$ & $0(0.2)$ & $0.2(0.4)$ \\
\hline context effect & $2.6(0.8)$ & $1.7(0.7)$ & $2.4(1.0)$ & & \\
\hline \multicolumn{6}{|l|}{ Old Age Group } \\
\hline \multicolumn{6}{|l|}{ RTs in ms } \\
\hline c-dep & 807 (48) & $828(52)$ & $844(54)$ & $-29(10)$ & $-16(11)$ \\
\hline c-indep & $609(23)$ & $607(23)$ & $609(25)$ & $1(4)$ & $-2(7)$ \\
\hline context effect & $198(34)$ & $221(38)$ & $235(41)$ & & \\
\hline \multicolumn{6}{|l|}{ Errors in \% } \\
\hline c-dep & $7.9(1.4)$ & $7.5(1.4)$ & $7.4(1.5)$ & $0.4(0.8)$ & $0.1(1.2)$ \\
\hline c-indep & $1.3(0.5)$ & $1.3(0.6)$ & $0.7(0.4)$ & $0.3(0.3)$ & $0.6(0.3)$ \\
\hline context effect & $6.6(1.2)$ & $6.1(1.6)$ & $6.7(1.5)$ & & \\
\hline
\end{tabular}

Context effect $=\mathrm{c}$-dep $-\mathrm{c}$-indep; Motivational salience effect $=$ neutral $-($ gain + loss $) / 2 ;$ Motivational valence effect $=$ gain - loss

$F(1,34)=5.2, p<.05, \eta_{\mathrm{p}}{ }^{2}=.13$, and a significant three-way interaction between age group, context condition, and motivational cue salience, $F(1,34)=10.8, p<.01, \eta_{\mathrm{p}}{ }^{2}=.24$. To focus on age differences in the motivational effects on context conditions, separate analyses for the two age groups were computed. In younger adults, we found a significant main effect of motivational cue salience, $F(1,34)=5.8, p<.05, \eta_{\mathrm{p}}{ }^{2}=.26$, and modulation of the context effects by motivational cue valence, $F(1,17)=6.2, p<.05, \eta_{\mathrm{p}}{ }^{2}=.27$. The latter effect was due to faster RTs on c-dep trials for gain than for loss trials, $F(1$, $17)=8.1, p<.05, \eta_{\mathrm{p}}{ }^{2}=.22$ (see Table 2). In older adults, context effects were modulated by motivational cue salience, $F(1,17)=10.4, p<.01, \eta_{\mathrm{p}}{ }^{2}=.38$. This interaction was due to longer latencies on c-dep trials for gain and loss than for neutral cues, $F(1,17)=8.4, p<.05, \eta_{\mathrm{p}}{ }^{2}=.38$ (see Table 2 ).

ERPs locked to the motivational cue

The ANOVA on the mean P2 amplitudes revealed a significant interaction between motivational cue salience and anterior-posterior, $F(1,34)=8.8, p<.01, \eta_{\mathrm{p}}{ }^{2}=.21$ - that is, larger P2 amplitudes for gain and loss cues than for neutral cues at central than at parietal electrode sites, $F(1,34)=8.8, p<.01$, $\eta_{\mathrm{p}}{ }^{2}=.21$ (see Fig. 2). The analysis of the P3b showed a more evenly distributed topography in older than in younger adults, $F(2,68)=18.9, p<.001, \eta_{\mathrm{p}}{ }^{2}=.36$. However, the ANOVA focused on non-vector-normalized data at electrode $\mathrm{Pz}$, where amplitudes were largest in both age groups (see Fig. 2). It showed an interaction between age group and motivational cue salience, $F(1,34)=8.2, p<.01, \eta_{\mathrm{p}}{ }^{2}=.19$ (see Fig. 2 ) that is, gain and loss cues elicited larger P3b amplitudes than did neutral cues in both age groups [younger adults, $F(1,17)=$ $40.9, p<.001, \eta_{\mathrm{p}}{ }^{2}=.71$; older adults, $F(1,17)=12.5, p<.01$, $\left.\eta_{\mathrm{p}}{ }^{2}=.42\right]$, but this effect was larger in younger adults, as can be inferred from the effect sizes. In sum, critical during the processing of motivational cue information was the salience of the cues, because anticipated gains and losses elicited larger P2 and P3b amplitudes than did neutral cues. For the P3b, this effect was more pronounced for younger than for older adults.

\section{ERPs locked to the context cue}

The analysis showed significant motivational cue valence effects in both age groups, $F(1,34)=5.8, p<.05, \eta_{\mathrm{p}}{ }^{2}=.15$, indicating larger P3b amplitudes on gain than on loss cues, and a significant three-way interaction between motivational cue salience, context condition, and age group, $F(1,34)=4.6, p$ $<.05, \eta_{\mathrm{p}}{ }^{2}=.12$. Since this three-way interaction did not interact with anterior-posterior, and in analogy to the analysis in the motivational cue interval, the further analyses focused on electrode $\mathrm{Pz}$, at which the $\mathrm{P} 3 \mathrm{~b}$ was maximal in both age groups. Here, we found a significant effect of motivational cue salience on context conditions only in older adults, $F(1,17)=4.7, p<.05$, $\eta_{\mathrm{p}}{ }^{2}=.22$, which was due to reduced $\mathrm{P} 3 \mathrm{~b}$ amplitudes on gain 
Fig. 2 Grand average waveforms elicited by neutral, gain, and loss motivational cues at three midline electrodes over the frontal $(\mathrm{Fz})$, central $(\mathrm{Cz})$, and parietal $(\mathrm{Pz})$ regions, shown separately for younger and older participants. The time windows used for the statistical analysis are highlighted (gray bars). Motivationally salient gain and loss cues elicited larger $\mathrm{P} 2 \mathrm{~s}$ and $\mathrm{P} 3 \mathrm{bs}$ than did neutral cues, and for the $\mathrm{P} 3 \mathrm{~b}$, this motivational salience effect was attenuated in older adults at electrode Pz. For visual presentation, the waveforms were low-pass filtered at $12 \mathrm{~Hz}$

\section{Younger adults}

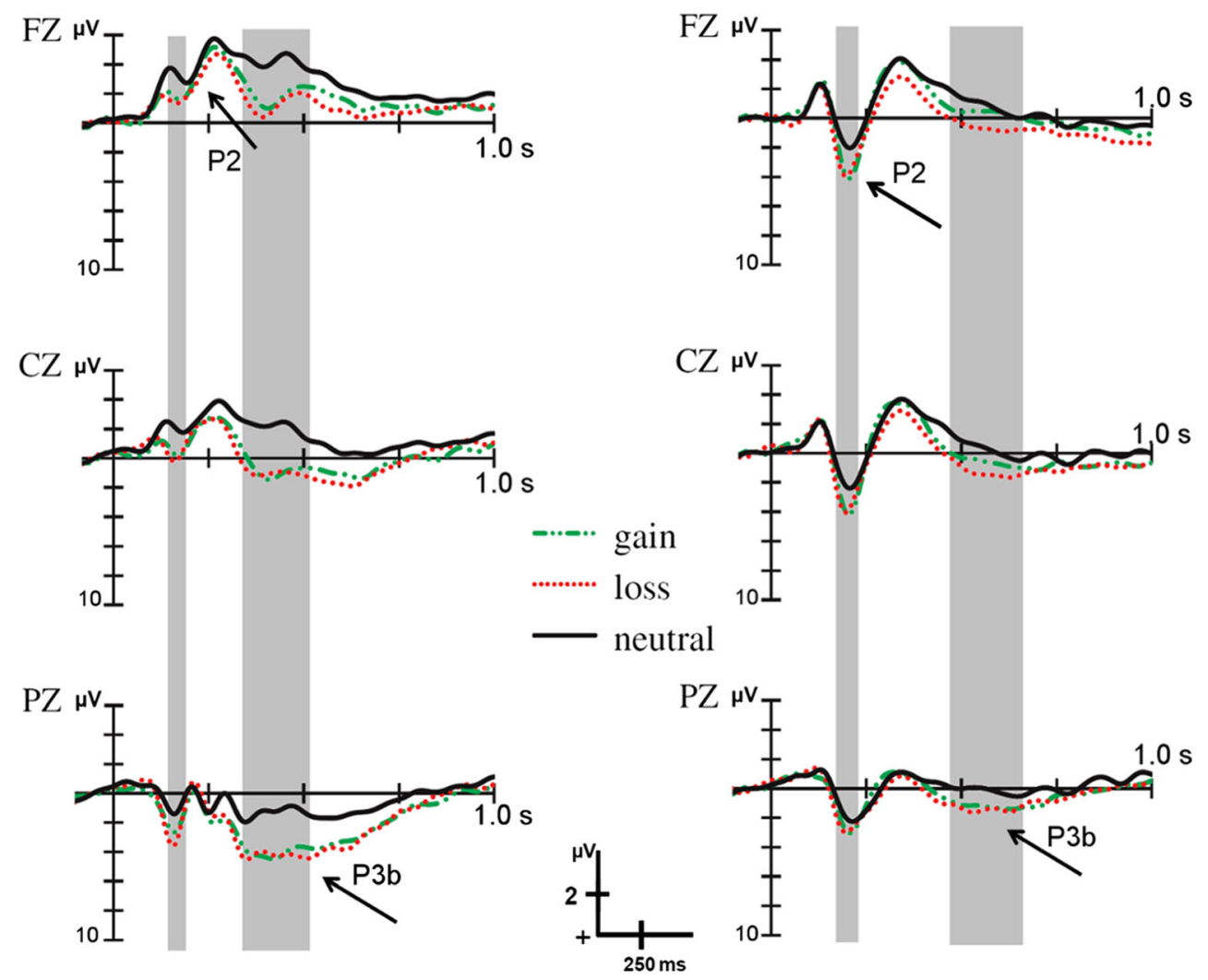

\section{Older adults}

and loss as compared to neutral cues, for c-indep trials only, $F(1,17)=11.0, p<.01, \eta_{\mathrm{p}}{ }^{2}=.39$ (see Fig. 3).

The analysis of the CNV showed age-differential effects for motivational cue valence in CNV amplitudes, $F(1,34)=$ $6.4, p<.05, \eta_{\mathrm{p}}{ }^{2}=.16$ - that is, only younger adults exhibited more negative-going $\mathrm{CNV}$ amplitudes on loss than on gain trials, $F(1,17)=12.6, p<.01, \eta_{\mathrm{p}}{ }^{2}=.43$ (see Fig. 4). Additionally, a three-way interaction between context condition, motivational cue salience, and anterior-posterior was found, $F(1,34)=6.0, p<.05, \eta_{\mathrm{p}}{ }^{2}=.15$, indicating that context effects were only significant for motivationally salient cues at electrode $\mathrm{Cz}, F(1,35)=5.9, p<.05, \eta_{\mathrm{p}}{ }^{2}=.15$. In sum, in the context cue interval, we found a context effect in P3b amplitudes on motivationally salient cues only for older adults, whereas this was not the case for younger adults. However, in the later $\mathrm{CNV}$ time window, a motivational cue valence effect was found for younger adults only, irrespective of the context condition.

\section{ERPs locked to the probe}

In the 300- to 600-ms interval, the ANOVA revealed a significant interaction between age group, context condition, motivational cue salience, and anterior-posterior, $F(4,136)=14.9, p<.001$, $\eta_{\mathrm{p}}{ }^{2}=.31$. Because we hypothesized age differences in motivational effects on context processing, separate analyses were computed for each age group. In younger adults, we found a significant interaction between motivational cue valence, context condition, and anterior-posterior, $F(1,17)=8.4, p<.05, \eta_{\mathrm{p}}{ }^{2}=.33$. This effect was due to a fronto-centrally distributed context effect for loss trials only, $F(1,17)=4.6, p<.05, \eta_{\mathrm{p}}{ }^{2}=.21$ [significant at $\mathrm{Cz}, F(1,17)=7.1, p<.05, \eta_{\mathrm{p}}{ }^{2}=.29$, and Fz, $F(1,17)=5.5, p<$ $.05, \eta_{\mathrm{p}}{ }^{2}=.25$; see Fig. 5]. In older adults, we observed a significant interaction between motivational cue salience, context condition, and anterior-posterior, $F(1,17)=16.6, p<.01, \eta_{\mathrm{p}}{ }^{2}=.49$. This effect was due to context effects for gain and loss cues only [significant at Fz, $F(1,17)=4.6, p<.05, \eta_{\mathrm{p}}{ }^{2}=.21$, and $\mathrm{Pz}, F(1$, 17) $\left.=8.9, p<.01, \eta_{\mathrm{p}}{ }^{2}=.34\right]$. In the 600 - to $900-\mathrm{ms}$ interval, the ANOVA revealed a significant four-way interaction between age group, context condition, motivational cue valence, and anterior-

Fig. 3 Grand average waveforms elicited by context cues on c-dep and cindep trials at three midline electrodes over frontal (Fz), central $(\mathrm{Cz})$, and parietal $(\mathrm{Pz})$ regions, shown separately for neutral, gain, and loss trials, and for younger and older participants. Gray bars indicate the respective time windows used for statistical analyses of the P $3 b$. Context effects (i.e., the difference between c-dep and c-indep trials) in parietal P3b amplitudes were larger on motivationally salient trials than on neutral trials for older adults only. For visual presentation, the waveforms were low-pass filtered at $12 \mathrm{~Hz}$ 


\section{Younger adults}

neutral

gain

loss
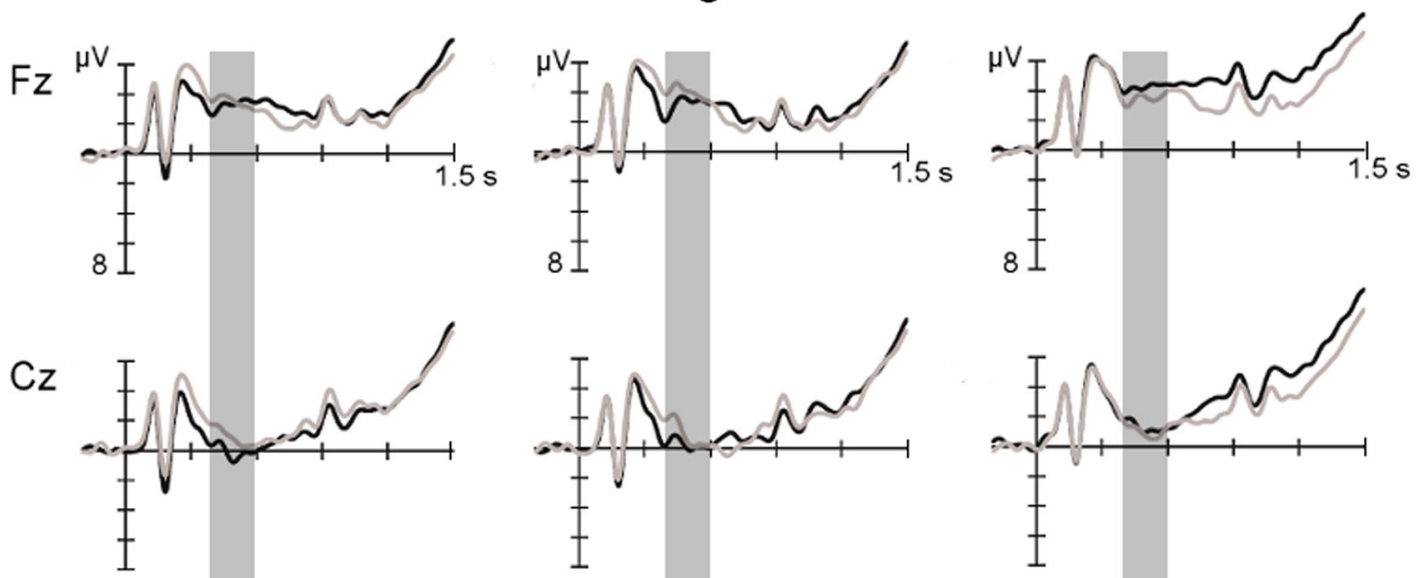

$\mathrm{P}_{z}$
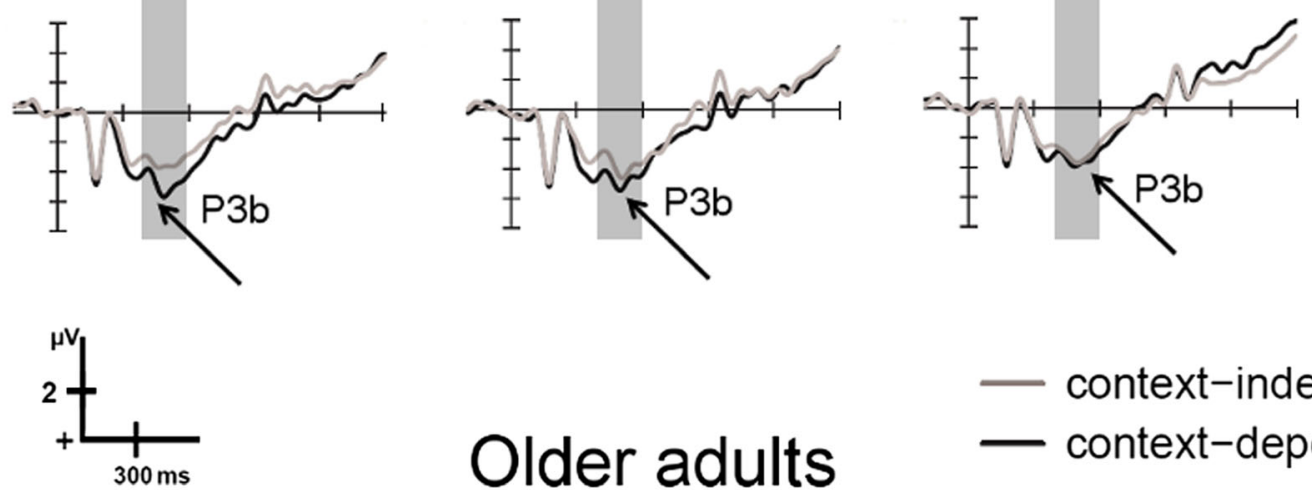

Older adults

— context-independent

neutral
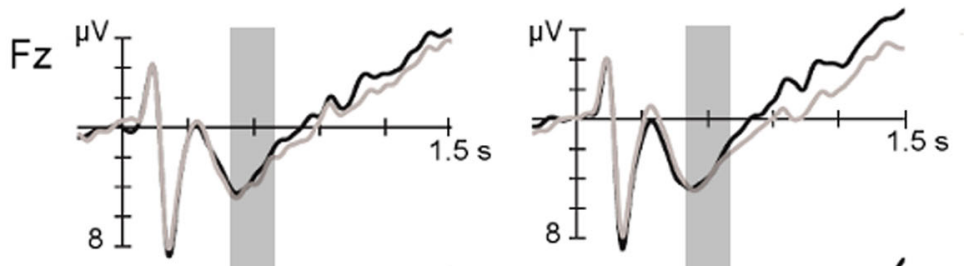

gain

- context-dependent
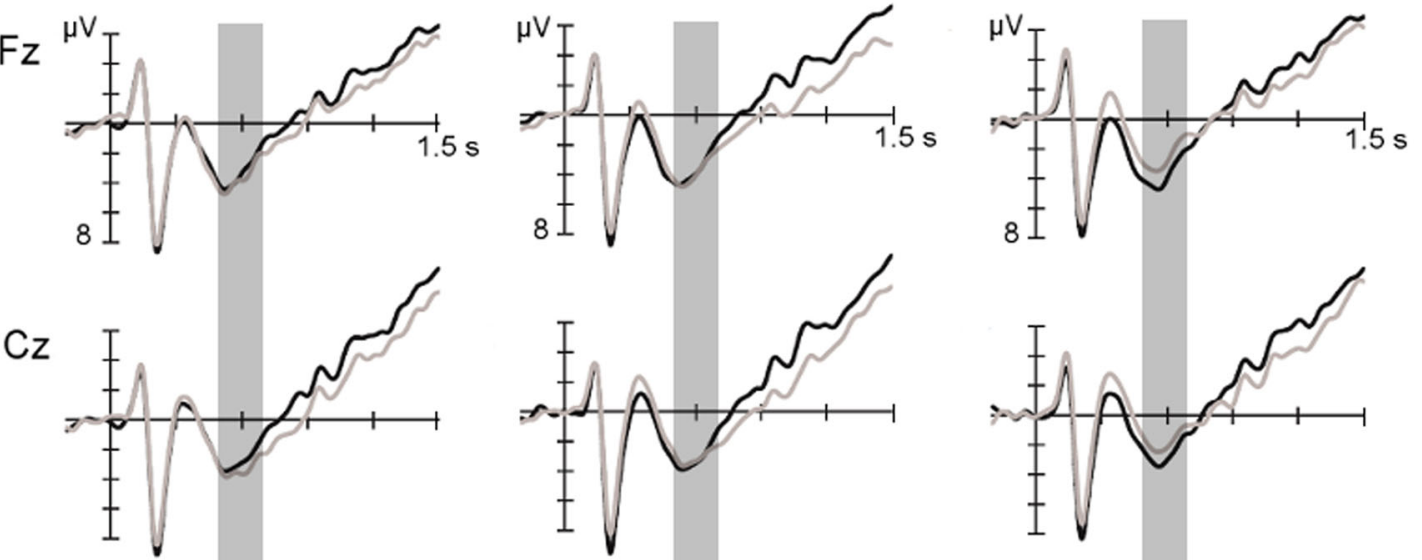

loss
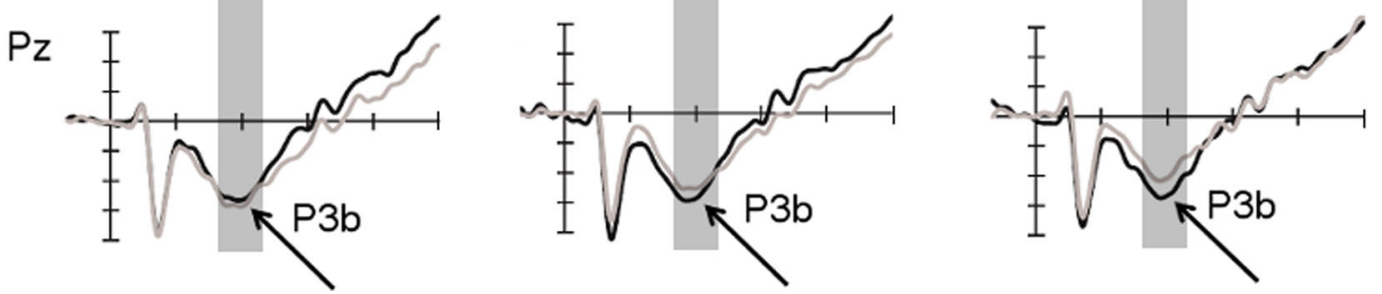
Fig. 4 Grand average waveforms elicited by context cues at three midline electrodes over frontal $(\mathrm{Fz})$, central $(\mathrm{Cz})$, and parietal $(\mathrm{Pz})$ regions, shown separately for neutral, gain, and loss trials, and for younger and older participants in the time window used for statistical analysis (gray bars). The mean CNV amplitudes were more negative-going on loss trials for younger adults only. For visual presentation, the waveforms were low-pass filtered at $12 \mathrm{~Hz}$

\section{Younger adults}
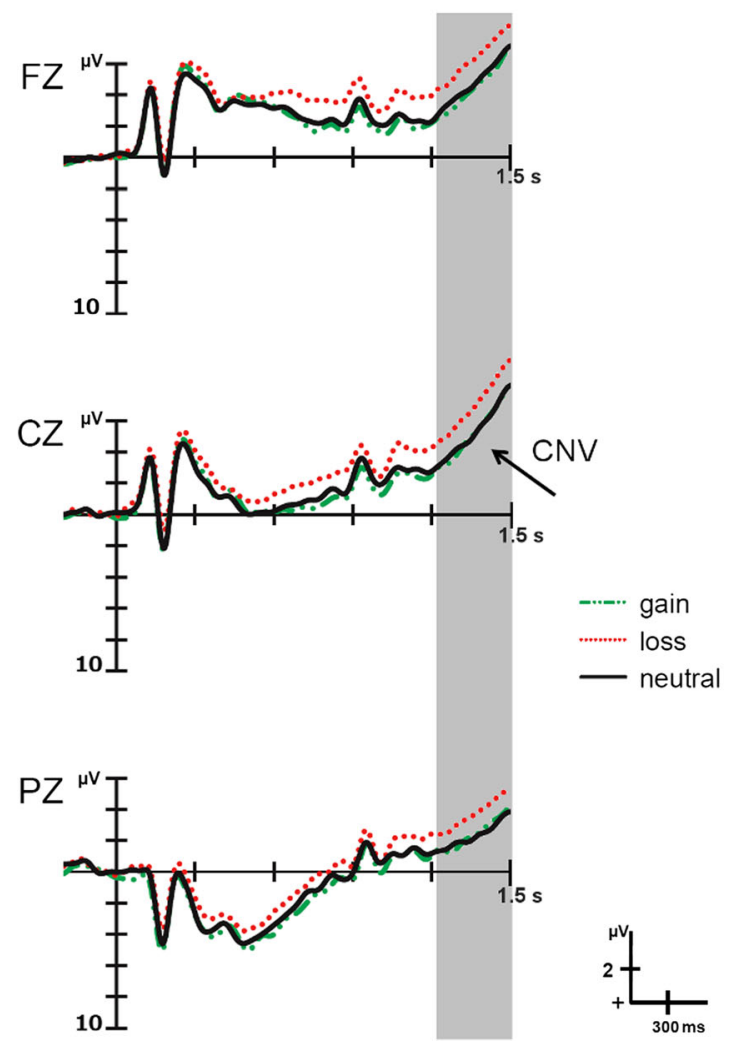

Older adults

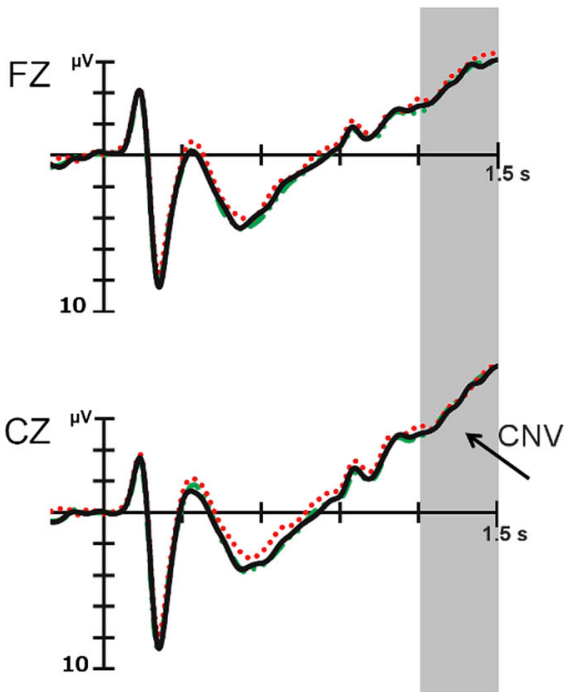

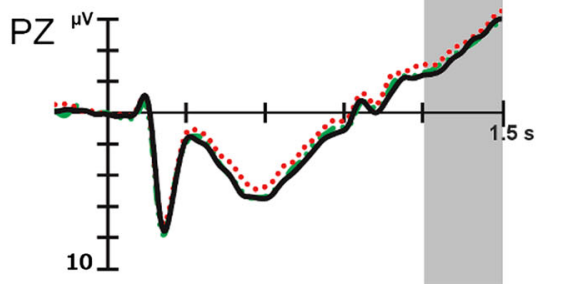

posterior, $F(1,34)=4.9, p<.05, \eta_{\mathrm{p}}{ }^{2}=.13$, and a marginally significant four-way interaction between age group, context condition, motivational cue salience, and anterior-posterior, $F(1,34)=3.2, p=.09, \eta_{\mathrm{p}}{ }^{2}=.09$. Separate analyses for both age groups revealed a motivational cue salience effect in younger adults, $F(1,17)=11.7, p<.01, \eta_{\mathrm{p}}{ }^{2}=.41$, indicating larger amplitudes on gain and loss than on neutral trials, as well as a modulation of context effects by motivational cue valence and anterior-posterior, $F(1,17)=3.2, p=.09, \eta_{\mathrm{p}}{ }^{2}=.16$. The latter effect was due to a reduced context effect at parietal electrodes on loss, $F(1,17)=5.9, p<.05, \eta_{\mathrm{p}}{ }^{2}=.26$, relative to gain, $F(1$, $17)=10.9, p<.05, \eta_{\mathrm{p}}{ }^{2}=.39$, trials (see Fig. 5). In older adults, context effects were modulated by motivational cue salience across electrodes; that is, context effects were significant for gain and loss cues at central, $F(1,17)=8.7, p<.01, \eta_{\mathrm{p}}{ }^{2}=$ .34 , and parietal, $F(1,17)=8.8, p<.01, \eta_{\mathrm{p}}{ }^{2}=.34$, electrodes (see Fig. 5), but not for neutral cues (all $p \mathrm{~s}>.11$ ). We also found a marginally significant interaction between motivational cue valence and anterior-posterior in older adults, $F(1,17)=$ $3.8, p=.07, \eta_{\mathrm{p}}{ }^{2}=.18$, indicating larger amplitudes on gain than on loss cues at $\mathrm{Cz}, F(1,17)=5.2, p<.05, \eta_{\mathrm{p}}{ }^{2}=.24$. In sum, in the probe-locked epoch, context effects were found on loss trials for younger adults in the early time window, which were slightly reduced as compared to gain trials in the later epoch. In older adults, context effects were absent on neutral trials, but present on motivationally salient cues during the entire probe epoch.

\section{Discussion}

In this study, we investigated the impact of motivational cues on age-related differences in context processing (Lenartowicz et al., 2010; Schmitt, Ferdinand, \& Kray, 2014). The discussion will first summarize the behavioral age differences in motivational effects on context processing and the processing of motivational cues with respect to the age-related positivity effect. Afterward, we will focus on the impacts of motivational salience and valence on the time course of context

Fig. 5 Grand average waveforms elicited by probes at three midline electrodes over frontal $(\mathrm{Fz})$, central $(\mathrm{Cz})$, and parietal $(\mathrm{Pz})$ regions, shown separately for neutral, gain, and loss trials, and for younger and older participants. Gray bars indicate the early (300-600 ms) and late (600-900 ms) time windows after probe presentation that were used for statistical analyses. Red lines indicate context effects (i.e., the difference between c-dep and c-indep trials). In the early time window, younger adults showed context effects exclusively on loss trials, whereas in the late epoch, context effects were attenuated for loss trials only. In contrast, older adults showed larger context effects on gain and loss than on neutral trials in both epochs. For visual presentation, the waveforms were lowpass filtered at $12 \mathrm{~Hz}$ 


\section{Younger adults}
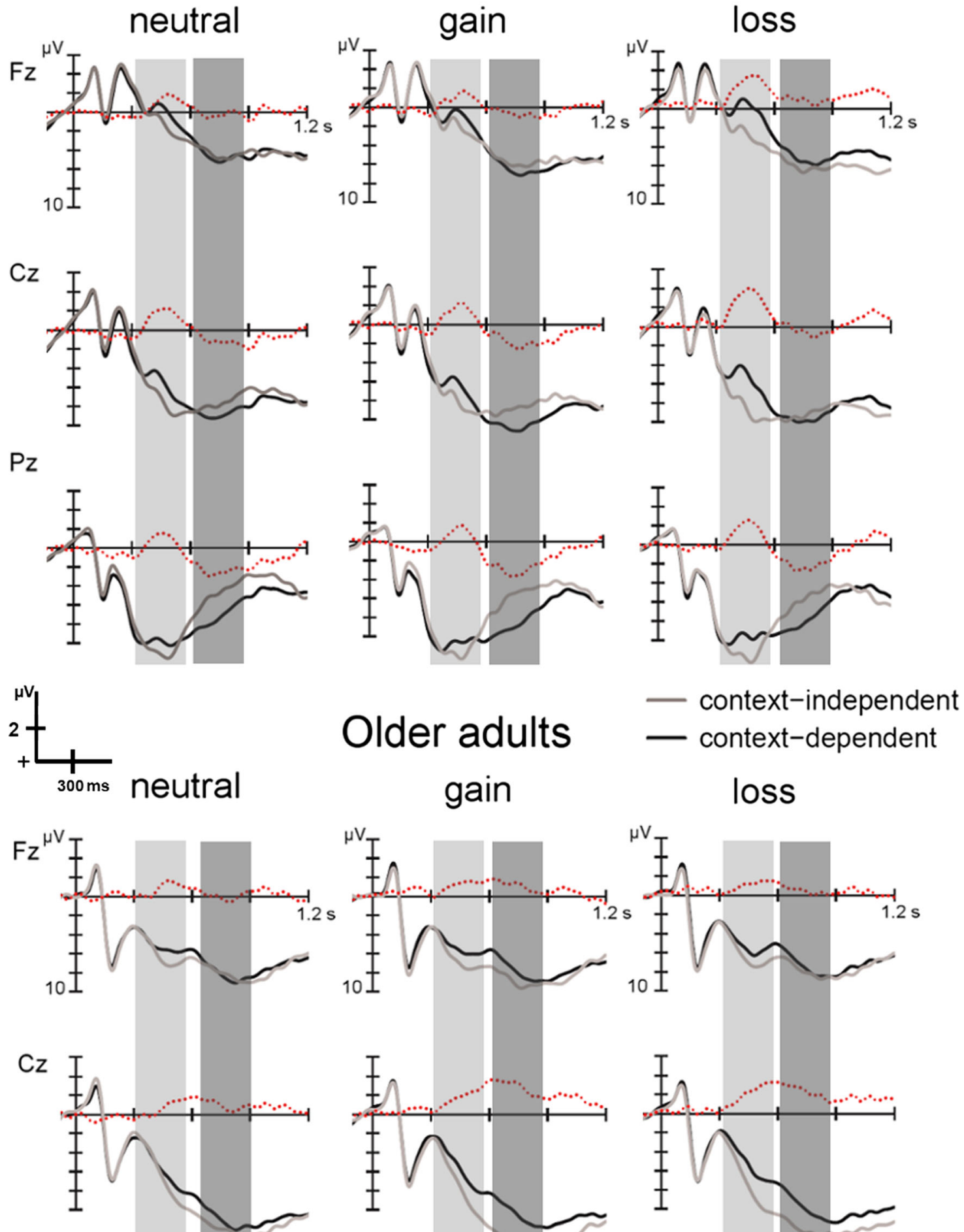

$\mathrm{Pz}$
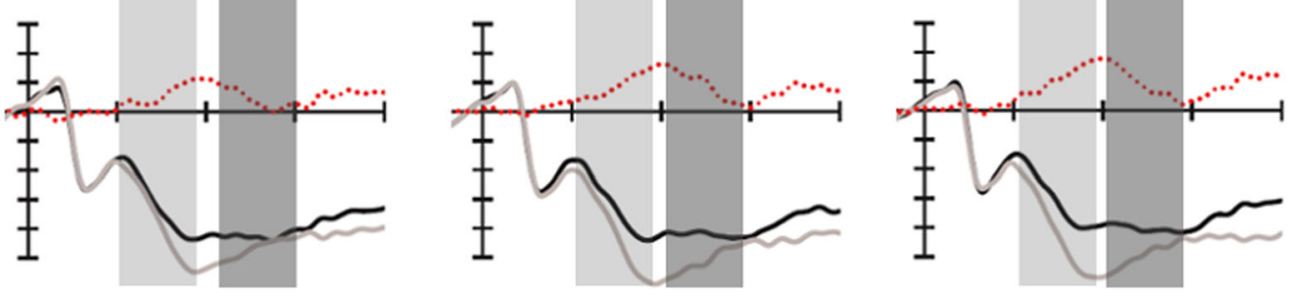
processing in a pro- and a reactive manner. Finally, implications concerning the DMC theory, previous findings on context representations in old age, and recent evidence of cognitive-affective interactions will be considered.

Age differences in behavioral salience and valence effects

In the RT data, younger adults benefited when motivational cues indicated potential gains, whereas older adults exhibited larger context effects in both gain and loss trials. The younger adults' reduced context effect on gain trials resulted from faster responding on c-dep trials, which is in accord with a previous study showing a speed-up in RTs under anticipated reward, even when performance was already good (Falkenstein et al., 2003). Importantly, this speed-up was not at the cost of errors, since we found no influence of the motivational cues on error rates (for similar results, see Chiew \& Braver, 2013; Kleinsorge \& Rinkenauer, 2012), suggesting a true enhancement of cognitive control by motivation (Pessoa \& Engelmann, 2010). This finding corresponds to the DMC theory (Braver \& Barch, 2002), since younger adults used the gain cue to trigger proactive context processing to respond quickly and accurately to the probe. It also extends previous studies that compared reward and penalty manipulations on cognitive control performance but that used different tasks for the two valence conditions (Locke \& Braver, 2008). Here, we showed evidence that under matched conditions, the improvement is substantially larger for reward than for penalty.

Contrary to the findings from younger adults, context effects in older adults were larger on gain and loss trials than on neutral trials. Since motivational cues did not affect error rates, this finding indicates that older adults were particularly cautious to respond correctly on c-dep trials whenever the motivational cue indicated the chance to win or the risk to lose money. Moreover, we found no evidence for a positivity effect in old age. In a recent review (Reed \& Carstensen, 2012), it has been shown that a positivity effect most likely occurs in conditions without experimental constraints on individual information processing, whereas explicit task instructions seem to reduce the age-related focus on positive information. Thus, since participants were explicitly informed about the importance of gains (positive) and losses (negative) for their monetary outcomes, older adults may have focused equally on both (Mather \& Carstensen, 2005). However, an investigation of the temporally more fine-grained ERPs will further shed light on the processing of motivational cues and the absence of a positivity effect.

Processing of motivational cues

First, ERPs time-locked to the motivational cues indicated larger P2 and P3b amplitudes for motivationally salient than for neutral cues. In line with the literature, larger P2 amplitudes to gain and loss cues have been linked to automatic attention capture by salient information (Carretié et al., 2004; for a review, see Olofsson et al., 2008), whereas larger P3b amplitudes to salient cues might indicate strategic processes of updating task-relevant stimulus information and the amount of attentional resources available for stimulus processing (Briggs \& Martin, 2009; Donchin \& Coles, 1988; Krebs et al., 2013; Olofsson et al., 2008; Polich, 2007). In the present study, the updating of task-relevant information provided by motivationally salient cues may have been useful for the gating of the following context information (Braver \& Barch, 2002; Gruber \& Otten, 2010).

Age differences were only present in larger parietal P3b amplitudes in younger than in older adults and more widespread activation across the scalp in the elderly. Although the age-related topography difference is a well-known finding (see Fabiani, Friedman, \& Cheng, 1998; Friedman, Nessler, Johnson, Ritter, \& Bersick, 2008), age differences in the anticipation of motivational events have only rarely been investigated and are not well understood (Olofsson et al., 2008; Samanez-Larkin et al., 2007; Wood \& Kisley, 2006). Hence, our study suggests that although the voluntary allocation of attention to process and update information about gains and losses, reflected in the $\mathrm{P} 3 \mathrm{~b}$, is compromised, the automatic processing of salient information, as reflected in the P2, is preserved in old age. In line with the behavioral data, we found no indication of a positivity effect in older adults, since they showed comparable P2 and P3b amplitudes to gain and loss cues.

Motivational influences on the ERP correlates of proand reactive control

The analysis of motivational salience and valence effects on the ERPs time-locked to the onset of the context cue and the probe revealed important new insights into the mechanisms underlying pro- and reactive context processing in younger and older adults. Whereas younger adults seemed to focus on the processing of negative events (i.e., losses), older adults showed a general modulation of context effects by salience. Importantly, these age-differential modulations took place within different stages of context processing. Younger adults showed an effect of cue valence on CNV amplitudes in the context cue epoch, in which amplitudes were more negative for loss trials. Thus, younger adults seemed to strongly engage in context maintenance whenever incorrect and slowed responses would be penalized. There is evidence that the amplitude of the $\mathrm{CNV}$ is related to the short-term mobilization of effort benefiting fast responding to an upcoming task (Falkenstein et al., 2003). However, in contrast to the present findings, the CNVs in the study by Falkenstein and colleagues were increased during reward as compared to neutral trials. One reason for this seeming discrepancy could be that 
Falkenstein et al. applied a simple choice RT paradigm in which the influence of penalties (i.e., for incorrect responding) was not assessed. Hence, although gain cues led to faster RTs, the $\mathrm{CNV}$ data suggest that younger adults more likely invested effort in the avoidance of losses. This might reflect an unconscious tendency to avoid a negative outcome rather than to attain gains (Krawczyk \& D'Esposito, 2013), which has also been shown in studies on decision making under risk (Kahneman \& Tversky, 1979).

Loss cues continued to have a powerful influence on context processing in younger adults in the probe epoch. In the early time window, context effects were found only in a fronto-centrally distributed component on loss trials. This negative-going deflection bears resemblance to the frontocentral N450 that has been linked to conflict processing in incongruent Stroop stimuli (Liotti et al., 2000; West et al., 2005). In the late probe epoch, context effects were found in a parietally distributed slow positive component (SP) that was reduced on loss trials. This component is similar to a parietal SP assumed to reflect conflict resolution, since it was larger for correct responses on incongruent Stroop trials (termed the LPC in Krebs et al., 2013, or the SP in West et al., 2005). It has also been associated with response selection, since its amplitude was significantly correlated with the general RT (West et al., 2005). Taken together, the results of the entire probe epoch suggest that when younger adults anticipate losses, they experience more response conflict on trials with reversed S-R assignments (i.e., on c-dep trials, as reflected in the N450) and engage more in its resolution (as reflected in the SP). This idea is fully in line with the behavioral results, indicating a larger context effect for loss than for gain trials.

An important new insight of the present study is that the analysis of cue- and probe-related ERPs indicated a differential modulation of context processing by motivational cues in older than in younger adults. In the P3b of the context-cue epoch, context effects were present in all motivational conditions for younger adults, whereas context effects were only found after motivationally salient cues in the elderly, corresponding to older adults' behavioral context effects. The absence of $\mathrm{P} 3 \mathrm{~b}$ context effects in neutral trials further replicates the results of our previous study (Schmitt, Ferdinand, \& Kray, 2014). In this study, we argued that older adults update context information on every trial, irrespective of the context condition, probably due to a failure to represent them differentially. Here, we present evidence that motivationally salient cues seem to modify this effect by decreasing context-updating effort on c-indep trials, and by this probably sharpening older adults' context representations.

In the probe epoch, the N450 on conflicting c-dep trials, reflecting conflict processing, was strongly reduced in older as compared to younger adults, and we observed no indication of a subsequent positivity reflecting conflict resolution. Instead, context effects in older adults were found under conditions of anticipated gains and losses in a probe-locked P3b across the two time windows. Thus, unlike younger adults, the temporally prolonged $\mathrm{P} 3 \mathrm{~b}$ suggests that increased WM recruitment was required for context updating and task reconfiguration before response execution. In our previous study, context effects in older adults were absent in the cue-locked ERPs, but present in the probe epoch (Schmitt, Wolff, et al., 2014). Here we showed evidence that the temporal shift of context processing toward reactive control in old age (Braver \& Barch, 2002 ) is engaged whenever the correctness of the response is important for the behavioral outcome - that is, during gain and loss trials. This finding corroborates older adults' longer RTs on motivationally salient trials.

Implications for the DMC account and cognitive-affective models

In sum, motivational cues appear to be an interesting tool for modulating behavioral performance and neuronal mechanisms of context processing. Although both age groups seem to use the motivational cues to prepare for the upcoming task, they use them in different manners. Although the time course of younger adults' context processing was strongly modulated by loss cues, context processing in older adults was consistently influenced by motivational salience.

Interestingly, our ERP results correspond to an fMRI study on the DMC model in younger adults, in which the researchers found neuronal activations indicating a trade-off between proand reactive control modes in blocked neutral, reward, and penalty conditions in the AX-CPT (Braver et al., 2009). On reward blocks, sustained activity was increased in a prefrontal network, reflecting increased proactive control linked to fast and correct responses. On penalty blocks, including monetary losses for errors in a no-go task, the time course of activity shifted within these brain regions to the onset of the probethat is, toward a reactive control mode. Although the neural sources underlying ERPs need to be treated cautiously, the present results together with the previous fMRI findings suggest that the avoidance of monetary losses shifts context processing in younger adults toward a reactivation of context information before task execution (Braver et al., 2009). Critically, context information might have been updated and encoded in the cue-probe epoch as well, since we found context effects in cue-locked P3b and CNV amplitudes. However, to avoid penalty on loss trials, younger adults seemed to process response conflict and interference more strongly, which might indicate the additional activation of performancemonitoring systems including the anterior cingulate cortex, which has been assumed to take part in mechanisms of reactive control (Braver et al., 2007). Besides, gain cues only affected the behavioral data, but not the ERPs, which was different from the increase in cue-related activity in the aforementioned fMRI study (Braver et al., 2009). However, the 
increase in cue-related fMRI activity was largest in highly reward-sensitive participants (Braver, 2012; Locke \& Braver, 2008). Since individual differences in personality factors were not assessed in the present study, a goal for future research should be to investigate individual differences in approach (and avoidance) motivations, temporal differences in context processing, and the underlying neuronal mechanisms. In this regard, it would also be interesting to apply measures that allowed for precise investigation of the influence of motivational variables on the DA-guided gating of context information into the PFC - for instance, using positron emission tomography or transcranial magnetic stimulation, as in the study by D'Ardenne et al. (2012).

Context processing in older adults was affected by motivationally salient cues: They showed enhanced processing of salient information provided by the gain and loss cues in the motivational cue interval, and subsequently, P3b amplitudes differed for the two context conditions only on motivationally salient trials. As compared to our previous study, in which (1) the amounts of context updating (indexed by P3b amplitudes) were similar for c-dep and c-indep trials (Schmitt, Ferdinand, \& Kray, 2014), and (2) context effects were found only in probelocked ERPs (Schmitt, Wolff, et al., 2014), the present results suggest that in conditions of high motivational salience, older adults exhibit a temporal shift toward a sharpened representation of context conditions that emerges as the context cues are first presented. This finding fits nicely with a previous AMRI study on context processing in the AX-CPT that showed a flexible shift from probe- toward cue-based PFC activation after strategy training in older adults (Braver et al., 2009). This shift might have been triggered by increased prestimulus activity elicited by the motivational cues (Gruber \& Otten, 2010), which could reflect increased attention to goal-relevant information (Krebs et al., 2013). However, the precise mechanisms underlying this benefit warrant future investigation.

It should be noted that, unlike the assumptions of the DMC theory (Braver \& Barch, 2002; Braver et al., 2009), we do not assume that the increase in cue-locked context effects in motivationally salient trials in older adults reflects a normalization of age-related differences in the neuronal mechanisms underlying context updating. Rather, we propose that motivational cues lead to an early representation of context conditions, in addition to probe-locked context effects (Schmitt, Wolff, et al., 2014). Interestingly, these probe-locked context effects were particularly pronounced during gain and loss trials, suggesting that older adults still experienced response conflict and the need to reactivate context conditions during probe presentation. The increase in probe-locked P3b amplitudes on motivational trials might also explain the larger behavioral context effects during gain and loss cues in older adults.

Finally, this study is also of particular interest for neurocognitive theories assuming that functionally specialized "cold" - that is, cognitive - and "hot" - that is, affective- processes are highly interactive in cognitive control (Gray, 2004; Gray, Braver, \& Raichle, 2002; Kerr \& Zelazo, 2004; Pessoa, 2008). Here we present empirical data that shed further light on the question of how affective and cognitive processes might be integrated and how this changes with age. Specifically, the ability to engage cognitive control in our task (reflected in the context effect) was flexibly modulated by motivationally salient cues and reflected in specific stages of context processing. This finding extends the previous literature highlighting the interaction of cognitive and affective processes (Gray, 2004; Pessoa, 2008), and provides evidence for a well-preserved interaction between cognitive and affective processes in old age. Since affective states are thought to bias control processes to meet personal goals (Gray, 2004), it is obvious that these goals were different for the two age groups - that is, related to the avoidance of losses in younger and the processing of salience in older adults. In this respect, examining whether the type of motivational manipulation applied may have differential impacts in the two age groups is an aim for future research. For example, since individual differences in reward sensitivity on cognitive control have already been established (Braver, 2012; Locke \& Braver, 2008), the avoidance of monetary loss might be a highly relevant goal in younger adults (depending on their financial situation), whereas older adults may prioritize social goals (depending on their communal position).

\section{Conclusion}

Our study has shown that motivational cues are valuable means to modulate context processing in younger and older adults. In conditions of potential monetary gains, context updating in younger adults was strengthened, whereas older adults showed increased effort for context processing in conditions of motivational salience. The ERP approach was helpful as a means to precisely uncover the stages of context processing underlying this modulation. Both age groups showed enhanced attentional processing of motivational cues. In younger adults, loss trials gave rise to an increase in context maintenance, as well as to enhanced processing of response conflict, associated with probe-locked ERPs. Thus, negatively valenced cues seem to trigger reactive control processes in addition to the proactive mode usually found in context processing in younger adults. In older adults, motivationally salient cues led to an early differentiation between context conditions, but also to an increase in WM recruitment during task execution. These results suggest that during motivational trials, older adults were able to represent the two context conditions at an early phase, but the importance of gaining or losing money still resulted in prolonged context updating before response execution. Since motivational valence and salience effects were clearly divergent for the two age groups, further studies will be necessary to investigate the neuronal 
mechanisms underlying age and individual differences in sensitivity to reward and penalty.

Acknowledgments This research was supported by the German Research Foundation (Grant No. IRTG-1457). We thank Maren Wolff, Cindy Nieser, and Aline Becker for the data collection.

\section{References}

Ashby, F. G., Isen, A. M., \& Turken, U. (1999). A neuropsychological theory of positive affect and its influence on cognition. Psychological Review, 106, 529-550. doi:10.1037/0033-295X.106.3.529

Bäckman, L., \& Farde, L. (2005). The role of dopamine systems in cognitive aging. In R. Cabeza, L. Nysberg, \& D. Park (Eds.), Cognitive neuroscience of aging (pp. 58-84). New York, NY: Oxford University Press.

Baltes, P. B., Lindenberger, U., \& Staudinger, U. M. (1998). Life-span theory in developmental psychology. In W. Damon \& R. Lerner (Eds.), Handbook of child psychology: Vol. 1. Theoretical models of human development (pp. 1029-1143). New York, NY: Wiley.

Begleiter, H., Chou, B. C., \& Aunon, J. I. (1983). P3 and stimulus incentive value. Psychophysiology, 20, 95-101.

Braver, T. (2012). The variable nature of cognitive control: A dual mechanism framework. Trends in Cognitive Sciences, 16, 106-113. doi: 10.1016/j.tics.2011.12.010

Braver, T. S., \& Barch, D. M. (2002). A theory of cognitive control, aging cognition, and neuromodulation. Neuroscience \& Biobehavioral Reviews, 26, 809-817. doi:10.1016/S0149-7634(02)00067-2

Braver, T. S., Barch, D. M., Keys, B. A., Carter, C. S., Cohen, J. D., Kaye, J. A., \& Reed, R. (2001). Context processing in older adults: Evidence for a theory relating cognitive control to neurobiology in healthy aging. Journal of Experimental Psychology: General, 130, 746-763. doi:10.1037/0096-3445.130.4.746

Braver, T. S., \& Cohen, J. D. (2000). On the control of control: The role of dopamine in regulating prefrontal function and working memory. In S. Monsell \& J. Driver (Eds.), Control of cognitive processes: Attention and performance XVIII (pp. 713-738). Cambridge, MA: MIT Press.

Braver, T. S., Gray, J. R., \& Burgess, G. C. (2007). Explaining the many varieties of working memory variation: Dual mechanisms of cognitive control. In A. R. Conway, C. Jarrold, M. J. Kane, A. Miyake, \& J. N. Towse (Eds.), Variation in working memory (pp. 76-106). New York, NY: Oxford University Press.

Braver, T. S., Paxton, J. L., Locke, H. S., \& Barch, D. M. (2009). Flexible neural mechanisms of cognitive control within human prefrontal cortex. Proceedings of the National Academy of Science, 106, 7351-7356. doi:10.1073/pnas.0808187106

Braver, T. S., \& West, R. (2008). Working memory, executive control, and aging. In F. I. M. Craik \& T. A. Salthouse (Eds.), Handbook of aging and cognition (pp. 311-372). New York, NY: Psychology Press.

Briggs, K. E., \& Martin, F. H. (2009). Affective picture processing and motivational relevance: Arousal and valence effects on ERPs in an oddballl task. International Journal of Psychophysiology, 72, 299-306.

Bromberg-Martin, E. S., Matsumoto, M., \& Hikosaka, O. (2010). Dopamine in motivational control: Rewarding, aversive, and alerting. Neuron, 68, 815-834. doi:10.1016/j.neuron.2010.11.022

Capa, R. L., Bouquet, C. A., Dreher, J.-C., \& Dufur, A. (2013). Longlasting effects of performance-contingent unconscious and conscious reward incentives during cued task-switching. Cortex, 49, 1943-1954.

Carretié, L., Hinojosa, J. A., Martín-Loeches, M., Mercado, F., \& Tapia, M. (2004). Automatic attention to emotional stimuli: Neural correlates. Human Brain Mapping, 22, 290-299. doi:10.1002/ hbm.20037

Chiew, K. S., \& Braver, T. S. (2011). Positive affect versus reward: Emotional and motivational influences on cognitive control. Frontiers in Psychology, 2(279), 1-10. doi:10.3389/fpsyg.2011. 00279

Chiew, K. S., \& Braver, T. S. (2013). Temporal dynamics of motivationcognitive control interactions revealed by high-resolution pupillometry. Frontiers in Psychology, 4(15), 1-15. doi:10.3389/ fpsyg.2013.00015

Chiew, K. S., \& Braver, T. S. (2014). Dissociable influences of reward motivation and positive emotion on cognitive control. Cognitive, Affective, \& Behavioral Neuroscience, 14, 509-529. doi:10.3758/ s13415-014-0280-0

D’Ardenne, K., Eshel, N., Luka, J., Lenartowicz, A., Nystrom, L. E., \& Cohen, J. D. (2012). Role of prefrontal cortex and the midbrain dopamine system in working memory updating. Proceedings of the National Academy of Sciences, 109, 19900-19909.

Donchin, E., \& Coles, M. (1988). Is the P300 component a manifestation of context updating? Behavioral and Brain Sciences, 11, 357-427.

Engelmann, J. B., \& Pessoa, L. (2007). Motivation sharpens exogenous spatial attention. Emotion, 7, 668-674.

Eppinger, B., Kray, J., Mecklinger, A., \& John, O. (2007). Age differences in task switching and response monitoring: Evidence from ERPs. Biological Psychology, 75, 52-67.

Fabiani, M., Friedman, D., \& Cheng, J. (1998). Individual differences in P3 scalp distribution in older adults, and their relationship to frontal lobe function. Psychophysiology, 35, 698-708.

Falkenstein, M., Hoormann, J., Hohnsbein, J., \& Kleinsorge, T. (2003). Short-term mobilization of processing resources is revealed in the event-related potential. Psychophysiology, 40, 914-923.

Ferdinand, N. K., \& Kray, J. (2013). Age-related changes in processing positive and negative feedback: Is there a positivity effect in older adults? Biological Psychology, 94, 235-241.

Friedman, D., Nessler, D., Johnson, R., Jr., Ritter, W., \& Bersick, M. (2008). Age-related changes in executive function: An eventrelated potential (ERP) investigation of task-switching. Aging, Neuropsychology, and Cognition, 15, 95-128. doi:10.1080/ 13825580701533769

Fröber, K., \& Dreisbach, G. (2014). The differential influences of positive affect, random reward, and performance-contingent reward on cognitive control. Cognitive, Affective, \& Behavioral Neuroscience, 14 , 530-547. doi:10.3758/s13415-014-0259-х

Goldstein, R. Z., Cottone, L. A., Jia, Z., Maloney, T., Volkow, N. D., \& Squired, N. K. (2006). The effect of graded monetary reward on cognitive event-related potentials and behavior in young healthy adults. International Journal of Psychophysiology, 62, 272-279.

Gratton, G., Coles, M. G. H., \& Donchin, E. (1983). A new method for off-line removal of ocular artifact. Electroencephalography and Clinical Neurophysiology, 55, 468-484. doi:10.1016/00134694(83)90135-9

Gray, J. R. (2004). Integration of emotion and cognitive control. Current Directions in Psychological Science, 13, 46-48.

Gray, J. R., Braver, T. S., \& Raichle, M. (2002). Integration of emotion and cognition in the lateral prefrontal cortex. Proceedings of the National Academy of Sciences, 99, 4115-4120.

Gruber, J. M., \& Otten, L. J. (2010). Voluntary control over prestimulus activity related to encoding. The Journal of Neuroscience, 30, 9793 9800.

Halsband, T. M., Ferdinand, N. K., Bridger, E. K., \& Mecklinger, A. (2012). Monetary rewards influence retrieval orientations. Cognitive, Affective, \& Behavioral Neuroscience, 12, 430-445. doi:10.3758/s13415-012-0093-y

Ikemoto, S., \& Panksepp, J. (1999). The role of nucleus accumbens dopamine in motivated behavior: A unifying interpretation with 
special reference to reward-seeking. Brain Research Reviews, 31, 641.

Jasper, H. H. (1958). Report of the Committee on Methods of Clinical Examination in Electroencephalography: 1957. Electroencephalography and Clinical Neurophysiology, 10, 370-375. doi:10.1016/0013-4694(58)90053-1

Jimura, K., Locke, H. S., \& Braver, T. S. (2010). Prefrontal cortex mediation of cognitive enhancement in rewarding motivational contexts. Proceedings of the National Academy of Sciences, 107, 8871-8876.

Kahneman, D., \& Tversky, A. (1979). Prospect theory: An analysis of decision under risk. Econometrica, 47, 263-292. doi:10.2307/ 1914185

Karayanidis, F., Coltheart, M., Michie, P. T., \& Murphy, K. (2003). Electrophysiological correlates of anticipatory and poststimulus components of task switching. Psychophysiology, 40, 329-348.

Kerr, A., \& Zelazo, P. D. (2004). Development of "hot" executive function: The children's gambling task. Brain and Cognition, 55, 148157.

Keselman, H. J., \& Rogan, J. C. (1980). Repeated measures $F$ tests and psychophysiological research: Controlling the number of false positives. Psychophysiology, 17, 499-503.

Kleinsorge, T., \& Rinkenauer, G. (2012). Effects of monetary incentives on task switching. Experimental Psychology, 59, 216-226.

Krawczyk, D. C., \& D'Esposito, M. (2013). Modulation of working memory function by motivation through loss-aversion. Human Brain Mapping, 34, 762-774. doi:10.1002/hbm.21472

Kray, J., Eppinger, B., \& Mecklinger, A. (2005). Age differences in attentional control: An event-related potential approach. Psychophysiology, 42, 407-416.

Kray, J., \& Lindenberger, U. (2000). Adult age differences in task switching. Psychology and Aging, 15, 126-147.

Krebs, R. M., Boehler, C. N., Appelbaum, L. G., \& Woldorff, M. G. (2013). Reward associations reduce behavioral interference by changing the temporal dynamics of conflict processing. PLoS ONE, 8(e53894), 1-10. doi:10.1371/journal.pone.0053894

Lehrl, S. (1977). Mehrfachwahl-Wortschatz-Test, Form B. Erlangen, Germany: Straube.

Lenartowicz, A., Escobedo-Quiroz, R., \& Cohen, J. D. (2010). Updating of context in working memory: An event-related potential study. Cognitive, Affective, \& Behavioral Neuroscience, 10, 298-315. doi:10.3758/CABN.10.2.298

Leon, M. I., \& Shadlen, M. N. (1999). Effect of expected reward magnitude on the response of neurons in the dorsolateral prefrontal cortex of the macaque. Neuron, 24, 415-425.

Lindenberger, U., Mayr, U., \& Kliegl, R. (1993). Speed and intelligence in old age. Psychology and Aging, 8, 207-220.

Liotti, M., Woldorff, M. G., Perez, R., III, \& Mayberg, H. S. (2000). An ERP study of the temporal course of the Stroop color-word interference effect. Neuropsychologia, 38, 701-711.

Locke, H. S., \& Braver, T. S. (2008). Motivational influences on cognitive control: Behavior, brain activation, and individual differences. Cognitive, Affective, \& Behavioral Neuroscience, 8, 99-112. doi:10. 3758/CABN.8.1.99

Luck, S. J., \& Hillyard, S. A. (1994). Electrophysiological correlates of feature analysis during visual search. Psychophysiology, 31, 209-308.

Mather, M., \& Carstensen, L. L. (2005). Aging and motivated cognition: The positivity effect in attention and memory. Trends in Cognitive Sciences, 9, 496-502. doi:10.1016/j.tics.2005.08.005

McCarthy, G., \& Wood, C. C. (1985). Scalp distributions of event-related potentials: An ambiguity associated with analysis of variance models. Electroencephalography and Clinical Neurophysiology, 62, 203-208

Miller, E. K., \& Cohen, J. D. (2001). An integrative theory of prefrontal cortex function. Annual Review of Neuroscience, 24, 167-202. doi: 10.1146/annurev.neuro.24.1.167
Minear, M., \& Park, D. C. (2004). A lifespan database of adult facial stimuli. Behavior Research Methods, Instruments, \& Computers, 36, 630-633. doi:10.3758/BF03206543

Oldfield, R. C. (1971). The assessment and analysis of handedness: The Edinburgh inventory. Neuropsychologia, 9, 97-113. doi:10.1016/ 0028-3932(71)90067-4

Olofsson, J. K., Nordin, S., Sequeira, H., \& Polich, J. (2008). Affective picture processing: An integrative review of ERP findings. Biological Psychology, 77, 247-265. doi:10.1016/j.biopsycho. 2007.11.006

Parvaz, M. A., Konova, A. B., Tomasi, D., Volkow, N. D., \& Goldstein, R. Z. (2012). Structural integrity of the prefrontal cortex modulates electrocortical sensitivity to reward. Journal of Cognitive Neuroscience, 24, 1560-1570.

Paxton, J., Barch, D., Racine, C., \& Braver, T. S. (2008). Cognitive control, goal maintenance, and prefrontal function in healthy aging. Cerebral Cortex, 18, 1010-1028.

Pessoa, L. (2008). On the relationship between emotion and cognition. Nature Reviews Neuroscience, 8, 148-158. doi:10.1038/nrn2317

Pessoa, L., \& Engelmann, J. B. (2010). Embedding reward signals into perception and cognition. Frontiers in Neuroscience, 4(17), 1-8. doi:10.3389/fnins.2010.00017

Polich, J. (2007). Updating P300: An integrative theory of P3a and P3b. Clinical Neurophysiology, 118, 2128-2148.

Raz, N. (2000). Aging of the brain and its impact on cognitive performance: Integration of structural and functional findings. In F. I. M. Craik \& T. A. Salthouse (Eds.), The handbook of aging and cognition (pp. 1-91). Mahwah, NJ: Erlbaum.

Rebai, M., Bernard, C., \& Lannou, J. (1997). The Stroop's test evokes a negative brain potential, the N400. International Journal of Neuroscience, 91, 85-94.

Reed, A. E., \& Carstensen, L. L. (2012). The theory behind the agerelated posivity effect. Frontiers in Psychology, 3(339), 1-9. doi: 10.3389/fpsyg.2012.00339

Rossion, B., \& Pourtois, G. (2004). Revisiting Snodgrass and Vanderwart's object pictorial set: The role of surface detail in basis-level object recognition. Perception, 33, 217-236. doi:10.1068/p5117

Samanez-Larkin, G. R., Gibbs, S. E., Khanna, K., Nielsen, L., Carstensen, L. L., \& Knuston, B. (2007). Anticipation of monetary gain but not loss in healthy older adults. Nature Neuroscience, 10, 787-791.

Schmitt, H., Ferdinand, N. K., \& Kray, J. (2014). Age-differential effects on updating cue information: Evidence from event-related potentials. Cognitive, Affective, \& Behavioral Neuroscience, 14, 11151131. doi:10.3758/s13415-014-0268-9

Schmitt, H., Wolff, M. C., Ferdinand, N. K., \& Kray, J. (2014). Age differences in the processing of context information: Is it age or is it performance? Journal of Psychophysiology, 28, $202-214$.

Schultz, W. (2002). Getting formal with dopamine and reward. Neuron, 9 , 241-269.

Unsworth, N., Heitz, R. P., Schrock, J. C., \& Engle, R. W. (2005). An automated version of the operation span task. Behavior Research Methods, 37, 498-505. doi:10.3758/BF03192720

Verleger, R., Jaśkowski, P., \& Wascher, E. (2005). Evidence for an integrative role of $\mathrm{P} 3 \mathrm{~b}$ in linking reaction to perception. Journal of Psychophysiology, 19, 165-181.

Watanabe, M. (1996). Reward expectancy in primate prefrontal neurons. Nature, 382, 629-631.

Wechsler, D. (2008). Wechsler Adult Intelligence Scale-Fourth edition (WAIS-IV). San Antonio, TX: Pearson Assessment.

West, R. L. (1996). An application of prefrontal cortex function theory to cognitive aging. Psychological Bulletin, 120, 272-292. doi:10. 1037/0033-2909.120.2.272

West, R. (2004). The effects of aging on controlled attention and conflict processing in the Stroop task. Journal of Cognitive Neuroscience, 16, 103-113. doi:10.1162/089892904322755593 
West, R., \& Alain, C. (2000). Effects of task context and fluctuations of attention on neural activity supporting performance of the Stroop task. Brain Research, 873, 102-111.

West, R., Jakubek, K., Wymbs, N., Perry, M., \& Moore, K. (2005). Neural correlates of conflict processing. Experimental Brain Research, 167, $38-48$.

West, R., \& Schwarb, H. (2006). The influence of aging and frontal function on the neural correlates of regulative and evaluative aspects of cognitive control. Neuropsychology, 20, 469-481. doi:10.1037/ 0894-4105.20.4.468

Wild-Wall, N., Hohnsbein, J., \& Falkenstein, M. (2007). Effects of ageing on cognitive task preparation as reflected by event-related potentials. Clinical Neurophysiology, 118, 558-569.

Wood, S., \& Kisley, M. A. (2006). The negativity bias is eliminated in older adults: Age-related reduction in event-related brain potentials associated with evaluative categorization. Psychology and Aging, 21, 815-820. 